University of Mannheim / Department of Economics

Working Paper Series

\title{
Platforms and network effects
}

\author{
Paul Belleflamme Martin Peitz
}

Working Paper 16-14

September 2016 


\title{
Platforms and network effects*
}

\author{
Paul Belleflamme ${ }^{\dagger}$ \\ Martin Peitz $\ddagger$ \\ Université catholique de Louvain \\ University of Mannheim
}

This version: September 2016

\begin{abstract}
In many markets, user benefits depend on participation and usage decisions of other users giving rise to network effects. Intermediaries manage these network effects and thus act as platforms that bring users together. This paper reviews key findings from the literature on network effects and two-sided platforms. It lays out the basic models of monopoly platforms and platform competition, and elaborates on some routes taken by recent research.
\end{abstract}

Keywords: Network effects, digital platforms, two-sided markets, tipping, platform competition, intermediation, pricing, imperfect competition

JEL-Classification: D43, L13, L86

${ }^{*}$ Chapter prepared for the forthcoming Handbook of Game Theory and Industrial Organization, edited by Luis Corchon and Marco Marini, Edward Elgar. We thank Markus Reisinger for helpful comments. Martin Peitz gratefully acknowledges financial support from the Deutsche Forschungsgemeinschaft (PE 813/2-2).

${ }^{\dagger}$ Université catholique de Louvain, CORE and Louvain School of Management, B-1348 Louvain la Neuve, Belgium, Paul.Belleflamme@uclouvain.be. Other affilitation: CESifo.

${ }^{\ddagger}$ Department of Economics and MaCCI, University of Mannheim, 68131 Mannheim, Germany, Martin.Peitz@gmail.com. Other affiliations: CEPR, CESifo, and ZEW. 


\section{Introduction}

Over the last two decades, the fast penetration of the Internet and the digitization of information products has led to the rise of electronic intermediaries such as Amazon, Google, and Facebook. Some of these intermediaries have become darlings on the stock market reflecting the believe that they have or will become central players in market economies. Of course, intermediaries are not a phenomenon of the internet, but have been around since ancient times. Many of these intermediaries play an important role because of supply-side or demand-side scale effects. Of particular importance are the latter, as many intermediaries require a certain volume of usage to attract additional users. This puts network effects at the core of intermediaries or, as we will call them, platforms.

A platform brings together a typically large number of users who interact with each other. For instance, the traditional telecommunications provider is such a platform that brings together people who may want to engage in communicating with each other. The more users on the network the more valuable the communication service. This is an example of direct network effects.

On many platforms we can distinguish between distinct groups of users, whose activities affect the well-being of those in another group. One example are software platforms: They bring together application developers and end users. Here, everything else given, end users may not care about the presence of other users, but only about the number and quality of application developers, while developers only care about the number and demand of end users. In this case, network effects are indirect, as end users care about participation and usage of other end users only indirectly, as more end users attract more developers which is beneficial for each end user. The platform managing the interaction among distinct groups of consumers is called two-sided. Some platforms allows for the interaction of buyers and sellers. Shopping malls are an example, as they offer retail space to sellers and invite buyers to go shopping. Everything else given, sellers prefer a shopping mall that attracts more buyers and buyers prefer a shopping mall that hosts more sellers. Trade fairs, flee markets, auction houses, and yellow pages have similar features. While some of these platforms have been around for centuries, platforms as a way to organize market activities have arguably gained more prominence with the rise of the internet. To enable consumers to choose among a myriad of offerings, horizontal and vertical search engines as well as price search engines, booking portals, online auction and retail places have become commonplace. As these digital platform are not subject to physical capacity constraints and can quickly guide a potential buyer to products of interest, they are able to manage huge volumes of interactions between buyers and sellers.

Platforms try to manage user participation and volumes of interaction. They can use price and non-price instruments for this purpose. In particular, they may court one particular group of users, e.g., buyers, to extract revenues from another group of users, e.g. sellers, who see the efforts of the platform to attract the first group of users. Managing users participation and volume of interaction thus depends on the ability of platforms to convince users about the 
decisions taken by other users. Users can become convinced because of past decisions other users have made (to the extent that they are not easily revised) or by a platform's actions such as publicly observed prices applicable to other users, which in turn affect expectations about the decisions these other users will make.

This chapter reviews some key contributions to the economics of network effects and twosided markets. In Section 2 we provide a discussion of network effects, criteria to classify different platform markets, and a number of examples. We explore the economics of markets with network effects in Section 3, and of two-sided markets in Section 4. Our aim is not to provide an exhaustive overview of the literatures on network effects and two-sided markets; instead, we pick a few contributions and elaborate on some key findings in a number of stylized settings. ${ }^{1}$

\section{Network effects and platforms: A first look}

In this section we give a definition of network effects, drawing a distinction between direct (within-group) and indirect (cross-group) effects. We also precise what we hear by 'platforms'. We then offer some illustrations.

\subsection{Defining network effects}

Network effects are present if users care about participation and usage decisions of other users. The group of users making the same usage decision is loosely called the 'network'. In the simplest setting, users care from an ex ante perspective only about the size of the network; in a more general setting, also the identity of the users of the network matters. For instance, social norms, languages and communication devices clearly generate positive network effects: the more they are adopted, the larger the utility they confer to their adopters. For a social norm, only the size of the network matters; in contrast, for communication means (e.g., a particular language or an instant messaging application), a user is primarily concerned with the decision of the subset of users with whom she has regular interactions; hence, the identity of the users of the network matters.

Network effects may emerge in a large variety of contexts and may be positive or negative depending on the circumstances. Road congestion and traffic jams are the prototypical examples of negative network effects: the more drivers choose a particular road at a particular moment, the slower the traffic on that road at that moment and, thereby, the lower the utility of every driver. Fashion and fads generate positive network effects for those individuals whose utility increases when they conform with the choices of others. Yet, the exact opposite applies for snobs, who value the idea of having different tastes then the 'mass': for them, having someone choosing like them generates a negative network effect - see, e.g., Grilo, Shy and Thisse (2001). Another example of positive network effects can be found in the choice of geographical locations by firms.

\footnotetext{
${ }^{1}$ To this end, we draw from and expand upon Chapters 20, 21, and 22 of Belleflamme and Peitz (2015).
} 
Following the seminal work of Marshall $(1890,1920)$, the economic geography literature explains why firms can benefit from locating close to one another; one explanation is that when more firms locate in the same region, more workers (or, more generally, input suppliers) are drawn to this region, which in turn makes the region more attractive for firms. ${ }^{2}$ We see in this last example that network effects do not arise directly from the firms making the same choice but indirectly through the induced decisions of another group of agents (i.e., workers and/or input suppliers).

To clarify what we will discuss in this chapter, we first distinguish between the direct and indirect sources of network effects; we then narrow our focus on so-called 'platforms', which somehow manage network effects.

\subsubsection{Within-group and cross-group external effects}

The number of participants and the intensity of use may affect a population of agents, as argued above. In many environments, we can distinguish different groups. One example are trading platforms on which buyers and sellers interact. In this case, positive cross-group external effects are present because buyers are, everything else given, better off the more sellers are present and vice versa. Another example are content platforms that carry advertising. Here, vertically integrated content is offered to entice consumers to join the platform. Consumers then may pay directly for participation or indirectly with their attention to advertising, which is bundled with content. If consumers' utility is decreasing in the volume of advertising, advertisers exert a negative cross-group external effect on consumers, while consumers exert a positive cross-group external effect on advertisers. In addition to cross-group effects, also within group external effects may be present. For instance, if the platform becomes congested if too many actors from one group participate, there are negative within-group external effects. Also, increased competition between sellers constitutes a negative within-group external effect on the seller side.

\subsubsection{Markets with platforms}

Markets with platforms can be broadly defined as markets where the interaction between at least some participants is facilitated and managed by an intermediary. Managing this interaction can take many forms; the most obvious ways are setting prices for participation or usage, or setting participation levels. The intermediary may have other instruments at its disposal. For instance, it may impose certain contractual terms, and it may provide monetary or non-monetary benefits for certain actions.

Our definition includes markets with a single group that exhibits within-group external effects, as long as an intermediary has at least one instrument to affect these within-group external effects and market outcomes. This sets our definition apart from recent definitions entering the policy debate, which require platforms to feature at least two sides (or two groups,

\footnotetext{
${ }^{2}$ For a comprehensive textbook on this topic, see Fujita and Thisse (2013).
} 
using our terminology). ${ }^{3}$ We believe that the broader definition serves the purposes of analyzing platform strategies (and, in particular, platform dynamics) better. The reason is that the property to feature only within-group external effects within a single group or also cross-group external effects with a second group is in some cases endogenous, i.e., it is a decision by the intermediary, as we illustrate below. Of course, there is no right or wrong definition. However, we believe that a broader definition is more appropriate, as it allows us to apply some economic mechanisms to this broad set of phenomena. Later on, it will be useful to dedicate particular attention to two-sided platforms, where additional issues arise.

\subsection{Illustrations}

Amazon and Facebook were initially one-sided platforms. Even today, their attractiveness depends to a large extent on the strength of positive within-group external effects. Amazon, by establishing its MarketPlace, added another group, namely independent sellers, which generates positive cross-group external effects between buyers and sellers. However, their main strength vis-a-vis rivals comes, arguably, from the positive within-group external effects on the buyer side, arising from its recommender and reputation systems (where the latter refers to the reviews and grades about products, not sellers). Facebook built its business model on providing advertisers the possibility of (targeted) advertising. To the extent that private users rather dislike advertising, Facebook is exploiting the user base it maintains because of the social networking benefits (which are within-group external effects) to provide benefits to advertisers. It then charges advertisers for this service. Here, users exert a positive cross-group external effect on advertisers, while advertisers exert a negative cross-group external effect on users. Clearly, advertising here serves as a monetization device (which benefits from a large, interconnected user base, as it allows for better targeting). However, the strength of Facebook in the market place is arguably due to within-group external effects arising from social networking among users. An alternative strategy by Facebook could have been to charge users for participation or usage. Using the narrower definition proposed elsewhere, Facebook would not be classified as a platform, even though the interaction between users would continue to be present.

Telecommunication networks also provide a nice illustration of the difficulty to draw a clear line between within- and cross-group external effects. Most of the economic literature on telecommunication networks assumes, for simplicity, uniform calling patterns, i.e., an equal likelihood for each subscriber to call and be called by any other subscriber; ${ }^{4}$ this assumption of fully symmetric participants implied a single group exhibiting within-group external effects. Another simplifying assumption would be to consider that some people only make calls, while others only receive calls (e.g., restaurants and customers who want to order for delivery or make a reserva-

\footnotetext{
${ }^{3}$ For instance, the European Commission (2015, p.5) gave the following definition: " 'Online platform' refers to an undertaking operating in two (or multi)-sided markets, which uses the Internet to enable interactions between two or more distinct but interdependent groups of users so as to generate value for at least one of the groups." See also Monopolkommission (2015) and House of Lords (2016).

${ }^{4}$ See, for instance, Armstrong (1998), Laffont, Rey, and Tirole (1998a, 1998b), and de Bijl and Peitz (2002).
} 
tion); in that case, there would be two distinct groups, with only cross-group external effects. The reality is naturally somewhere between these two extremes: subscribers are heterogeneous in their propensity both to make calls and to receive calls. Moreover, calling patterns are largely reported to be nonuniform: as indicated above, most subscribers have a 'calling circle', i.e., a subset of subscribers with whom they interact more frequently than with others. ${ }^{5}$ Seen from an individual subscriber's perspective, external effects are then mostly within-group (i.e., inside the calling circle), cross-group effects (i.e., outside the calling circle) being relatively limited; yet, each subscriber makes a different distinction between the two types of external effects as calling circles differ.

Finally, even if a platform facilitates the interaction between two distinct groups of users, some network effects may be jointly generated by all users, irrespective of the group they belong to, which may further blur the distinction between cross- and within-group external effects. Take the example of peer-to-peer marketplaces like Uber or Airbnb, which enable the interaction between providers and consumers of services; clearly, each group exerts positive cross-group external effects on the other group. Yet, the quality of the matching between peers from the two groups increases with the volume and reliability of data that the platforms collect from providers and consumers alike. Hence, a form of within-group external effects appears: the larger the participation on both sides, the more data is generated (about feedbacks, reputation, reviews, geo-localisation, etc.), which enhances the quality of the platform's service and, thereby, the utility of all users.

\section{Economics of markets with network effects}

In this section, we explore the economics of markets with network effects. We first focus on the demand side and derive the demand for a good that exhibits network effects. We then turn to the supply side, considering first markets with a single network good, provided either by a monopoly or by perfectly competitive firms. We move next to markets with several network goods supplied by distinct firms, where decisions about prices and capacities cannot be separated from decisions about compatibility.

\subsection{Demand for a network good}

To determine user demand in a market with network effects, we consider an intermediation market with a large number of potential users. ${ }^{6}$ The total number of potential users has measure $\bar{n}$. Each user $i$ is characterized by some stand-alone utility $r_{i}$ of using the services of the intermediary irrespective of the number of users. Users are distributed according to some cumulative distribution function $G$ defined on an interval $[\underline{r}, \bar{r}]$. The cumulative distribution function is continuous on its support and takes values $G(\underline{r})=0$ and $G(\bar{r})=1$.

\footnotetext{
${ }^{5}$ See, e.g., Hoernig, Inderst and Valletti (2014).

${ }^{6}$ Our exposition on the demand for network goods follows Belleflamme and Peitz (2015, Chapter 20).
} 
For the sake of simplicity, we focus on the participation decision of each user and do not look at the usage intensity. Each user $i$ pays a price $p_{i}$ for obtaining the possibility to interact with other users via an intermediary. When interacting, we assume that each user obtains an additional utility $u_{i}(n)$ that depends on the measure of participating users $n$. We set $u_{i}(0)=0$ for all users. In particular, if everybody with a stand-alone utility of $r_{i}$ and higher participates we have $n=\left(1-G\left(r_{i}\right)\right)$. A user may decide not to participate and obtain an outside valuation of $v_{0}=0$ or to be active and obtain valuation $r_{i}+u_{i}(n)-p_{i}$.

We consider two alternative specifications of heterogeneity among users, one with respect to $r_{i}$ and one with respect to $u_{i}$. Suppose first that all users have the same function $u(\cdot)=u_{i}(\cdot)$ and face the same price $p=p_{i}$. Consumers with a large $r_{i}$ tend to participate, while those with a low $r_{i}$ tend to be more reluctant. Suppose that there is an interior user with $\hat{r} \in(\underline{r}, \bar{r})$ that satisfies $\hat{r}+u((1-G(\hat{r})))-p=0$. Thus, when $u$ is downward sloping or not too strongly upward sloping, there exists a stable user equilibrium such that all consumers with $r_{i} \geq \hat{r}$ participate, while all users with $r_{i}<\hat{r}$ do not, with $\hat{r}+\varepsilon+u((1-G(\hat{r}+\varepsilon)))-p>0$ and $\hat{r}-\varepsilon+u((1-G(\hat{r}-\varepsilon)))-p<0$. There is a stable user equilibrium such that all users participate if the slope of $u$ is positive and sufficiently large, and $\underline{r}-p$ not too small such that $\underline{r}+u(\bar{n})-p \geq 0$.

It is important to note that in the presence of positive network effects, multiple equilibria may arise. That is, the same price may give rise to several equilibrium network sizes. For instance, if $\bar{r}<p=\hat{r}+u((1-G(\hat{r})))<\underline{r}+u(\bar{n})$, with $\hat{r} \in(\underline{r}, \bar{r})$, then on top of the interior equilbrium with a mass of $0<1-G(\hat{r})<\bar{n}$ users, no participation and full participation are also equilibria. As an illustration, suppose that $r_{i}$ is uniformly distributed on $[0,1]$, there is a mass one of users, and $u(n)=2 n$. Then, for $p=3 / 2$, the following three situations are equilibria: (i) no user participate (as the user with the largest stand-alone utility is not willing to pay the price when no other user participates: $1+2 \times 0<p=3 / 2$ ); (ii) the set of users with $r_{i} \geq 1 / 2$ participate (as $r_{i}=1 / 2$ is the indifferent user when the mass of participants is equal to $1 / 2$ : $1 / 2+2 \times 1 / 2=p=3 / 2$ ); (iii) all users participate (as the user with the lowest stand-alone utility is willing to pay the price when all other users participate: $0+2 \times 1>p=3 / 2$ ).

A special case is the situation in which users are homogeneous and the stand-alone utility is set equal to zero. Then, if users suffer from the presence of more users with the intermediary, there will not be any interaction for any positive price. However, if users benefit from the presence of other users such that $u$ is strictly increasing, there is a stable consumer equilibrium such that all consumers participate if $u(\bar{n})>p$.

Suppose next that all users have the same stand-alone utility but differ in their valuation of the interaction with other users. That is, $r_{i}=r$ for all users, while $u_{i}(n) \neq u_{j}(n)$ for $i \neq j$. As there are multiple ways in which the functions $u_{i}(\cdot)$ may differ, let us develop one specific example to show that multiple equilibria may arise as well under this alternative specification of user heterogeneity. Suppose that there is a unit mass of users $(\bar{n}=1)$, identified by a parameter $\theta$ that is uniformly distributed on $[0,1]$, and let user $\theta$ value the interaction with other users according to the function $u_{\theta}(n)=\theta n$. That is, we assume that network benefits increase linearly with the size of the network of participants but with a different intensity for each user. If all 
users face the same price $p$ to interact through the intermediary, the indifferent user is identified as $\hat{\theta}$ such that $r+\hat{\theta} n=p$. As all users with $\theta \geq \hat{\theta}$ will participate, the mass of participants is equal to $n=1-\hat{\theta}$, which implies that $\hat{\theta}=1-n$. It follows that the inverse demand for participation can be written as $p=r+n(1-n)$, which is a bell-shaped function of $n$ that reaches a maximum at $n=1 / 2$, where $p=r+1 / 4$. So, for any price $p \in(r, r+1 / 4)$, there are two 'demand levels', i.e., the two values of $n$ that solve $p=r+n(1-n)$. Moreover, $n=0$ is also compatible with such a price as in this case (i.e., if no user participate), each user has a negative net utility and finds thus optimal not to participate $\left(r+\theta \times 0-p<v_{0}=0\right.$ for all $\theta$ ). As above, we can thus find prices for which three equilibrium participation levels coexist. They all stem from 'self-fulfilling prophecies' insofar as they correspond to network sizes that generate utilities such that the combined participation decisions of the users exactly generate these network sizes.

\subsection{Monopoly provision of a network good}

Suppose that the network good is provided by a monopoly intermediary and that this intermediary is able to choose how many users to connect to the network. Suppose also that there is a constant marginal cost, $c \geq 0$, to connect an extra user to the network. By choosing the size of the network, the intermediary has the potential to internalize network effects as it recognizes that a larger network raises the users' willingness to pay and, thereby, its revenues. We may then wonder whether a monopoly intermediary does not have the incentive to extend the network up to the size that would prevail under perfect competition. However, this is generally not the case, as we now show in a simple example.

Consider a pure communication technology that generates only network benefits (the standalone utility is equal to zero for all users). As above, suppose that there is a unit mass of users $(\bar{n}=1)$, identified by a parameter $\theta$ that is uniformly distributed on $[0,1]$; user $\theta$ values the possibility to communicate with a mass $n$ of other users according to the function $u_{\theta}(n)=$ $\theta n$. Following the methodology developed above, we compute the inverse demand for network participation as $p=n(1-n)$. Note that the maximum price is reached for $n=1 / 2$ and is equal to $1 / 4$; we therefore assume that $c<1 / 4$ to make the problem non trivial. The intermediary chooses $n$ to maximize $n^{2}(1-n)-n c$. From the first- and second-order conditions, we find the profit-maximizing network size as $n^{m}=(1+\sqrt{1-3 c}) / 3$.

If the network good was supplied by a competitive industry, the network size $n^{c}$, would be such that $p=c$; that is $n^{c}\left(1-n^{c}\right)=c$, which is equivalent to $n^{c}=(1+\sqrt{1-4 c}) / 2$. It is easily checked that $n^{c}>n^{m}$, meaning that despite its ability to internalize network effects (which competitive firms lack), the monopoly intermediary still restricts the network size (i.e., the quantity) below the perfectly competitive level, thereby reducing welfare.

As far as welfare is concerned, it is important to note that in the presence of network effects, perfect competition generally also fails to achieve the first best. In our example, social welfare 
is maximized when all consumers join the network (i.e., $n^{*}=1$ ) but, for any $c>0, n^{c}<1 .^{7}$ Network effects are the source of the market failure: when joining the network, users do not internalize the positive consumption externality that they exert on the other users.

\subsection{Provision of competing network goods}

We consider now situations where users can choose among several substitutable network goods that are provided by different firms. As we will now discuss, the degree of compatibility among the various networks is of crucial importance since it conditions the network benefits that users enjoy when joining a particular network. If networks are fully incompatible, each firm makes up its own network, insofar as network benefits are product-specific. At the other extreme, when networks are fully compatible, each user generates network benefits for any user of any network alike; it is as though a single network existed. In between, there are situations of imperfect compatibility where network benefits are stronger among users of the same network than among users of different networks. As an illustration, think of using your smartphone for its primary function, that is to phone someone. If you use the regular phone lines, you do not need to worry about which operating system (OS) your correspondant has on her smartphone: there is full compatibility. In contrast, to make a video call through Facetime, users must both have an iPhone because this application, developed by Apple, is not available to users of devices running on other OSs than iOS; in this case, there is full incompatibility. As for partial compatibility, most 'Voice over IP' applications (e.g., Skype, Whatsapp or Viber) are available for all major OSs; yet, the performance of some apps may vary across OSs, which may cause problems (such as synchronization issues) when calls are made between different devices.

\subsubsection{A duopoly model}

To analyze the importance of compatibility, we develop the following model of competition between two producers of network goods. We follow the seminal work of Katz and Shapiro (1985) and its extension by Crémer, Rey and Tirole (2000). ${ }^{8}$ As for the demand side of the market, we assume that there are two types of users. On the one hand, a mass $\alpha$ of users have adopted the network good of firm $A$ in the past and are now locked in by the contract they have previously signed. These consumers, whom will be referred to as firm $A$ 's 'installed base', make no decision in the game but confer an advantage to firm $A$ over its competitor (we will therefore call firm $A$ the 'big firm'). On the other hand, there is a continuum of unattached users (of mass one) who are identified by a parameter $r$, which is drawn from a uniform distribution on the unit interval. These unattached (or 'new') users choose whether to adopt the network

\footnotetext{
${ }^{7}$ Social welfare is computed as $W(n)=\int_{1-n}^{1} \gamma n d \gamma-n c=\frac{1}{2} n^{2}(2-n)-n c$. We check that for all $0 \leq n<1$, $W(1)-W(n)=\frac{1}{2}(1-n)(1-2 c+n(1-n))>0$.

${ }^{8}$ Relatedly, Doganoglu and Wright (2006) analyze compatibility choice in a model with price-setting firms, where consumers can overcome incompatibility by multihoming - i.e., by buying the two incompatible versions. As they show, multihoming makes compatibility less attractive for firms, while it may make compatibility socially more desirable.
} 
good of firm $A$ or of firm $B$. Letting $r$ measure the stand-alone benefit of any network good, $g_{i}$ measure the network benefit from good $i$, and $p_{i}$ denote the price of good $i$, we have that a new user of type $r \in[0,1]$ obtains a net surplus from adopting the good of firm $i$ equal to $U_{i}(r)=r+g_{i}-p_{i}$. The network benefits generated by the two goods are defined respectively as $g_{A}=\nu\left(q_{A}+\alpha+\gamma q_{B}\right)$ and $g_{B}=\nu\left(q_{B}+\gamma q_{A}+\gamma \alpha\right)$. In these formulations, the parameter $\nu$ measures the strength of the network effects, $q_{i}$ is the number of new users joining network $i$, and the parameter $\gamma$ measures the degree of compatibility between the two goods. We assume that $\nu<1 / 2$ to guarantee the existence of a stable equilibrium; as for $\gamma$, it is bounded below by zero (full incompatibility) and above by one (full compatibility).

Regarding the supply side of the market, we assume that each good is produced at zero marginal cost. The two firms compete for the new users by choosing the capacity of their network (i.e., they compete à la Cournot). To derive the demand function facing each firm, we identify the new user $r_{0}$ who is exactly indifferent between the three options of joining network $A$, joining network $B$ or not joining any: $r_{0}+g_{A}-p_{A}=r_{0}+g_{B}-p_{B}=0$, which is equivalent to $r_{0}=\hat{p}$, where $\hat{p}=p_{A}-g_{A}=p_{B}-g_{B}$ is the common 'quality-adjusted price' of the two firms. As all new users with $r \geq r_{0}$ decide to join one or the other network (and given our assumption of a uniform distribution of $r$ ), we have that the total number of users is given by $q_{A}+q_{B}=1-\hat{p}$. Using the definitions of $\hat{p}, g_{A}$ and $g_{B}$, we can then write the inverse demand functions as

$$
\left\{\begin{array}{l}
p_{A}=1+\nu \alpha-(1-\nu) q_{A}-(1-\gamma \nu) q_{B}, \\
p_{B}=1+\gamma \nu \alpha-(1-\nu) q_{B}-(1-\gamma \nu) q_{A} .
\end{array}\right.
$$

We observe that the intercepts of both demands increase with the size of firm $A$ 's installed base but to a lower extent for firm $B$ than for firm $A$ if compatibility is not complete $(\gamma<1)$; we also observe that incompatibility introduces a form of horizontal differentiation among the two network goods as the price of good $i$ is more sensitive to a change in the capacity of network $i$ $\left(q_{i}\right)$ than of network $j\left(q_{j}\right)$.

Firm $i$ chooses its capacity $q_{i}$ to maximize its profit $\Pi_{i}=p_{i} q_{i}$. Solving for the system of first-order conditions, one finds the following equilibrium quantities:

$$
\begin{aligned}
& q_{A}^{*}=\frac{1}{3-(2+\gamma) \nu}+\frac{2-\gamma-\nu\left(2-\gamma^{2}\right)}{(3-(2+\gamma) \nu)(1-(2-\gamma) \nu)} \nu \alpha, \\
& q_{B}^{*}=\frac{1}{3-(2+\gamma) \nu}-\frac{1-(2-\nu) \gamma}{(3-(2+\gamma) \nu)(1-(2-\gamma) \nu)} \nu \alpha .
\end{aligned}
$$

From the first-order conditions, we easily find that $\Pi_{i}^{*}=(1-\nu)\left(q_{i}^{*}\right)^{2}$. As expected, the installed base $\alpha$ provides firm $A$ with a competitive advantage as it allows it to reach a larger capacity than its rival at equilibrium: we check that

$$
q_{A}^{*}-q_{B}^{*}=\frac{(1-\gamma) \nu}{1-(2-\gamma) \nu} \alpha>0
$$

We observe that the larger $\alpha$, the larger the advantage. This does not mean, however, that a sufficiently large installed base would necessarily drive firm $B$ out of the market. If the degree of compatibility is large enough, more precisely, if $\gamma>1 /(2-\nu)$, then firm $B$ 's users benefit 
sufficiently from the network effects generated by firm $A$ 's installed base to guarantee that $q_{B}^{*}>0 .{ }^{9}$ This also explains why enhanced compatibility reduces the difference between the equilibrium capacities of the two firms:

$$
\frac{d\left(q_{A}^{*}-q_{B}^{*}\right)}{d \gamma}=-\frac{1-\nu}{(1-(2-\gamma) \nu)^{2}} \alpha \nu<0
$$

As compatibility increases, the perceived quality differential between the two network goods is reduced, which reduces firm $A$ 's initial advantage.

The latter finding suggests that the big firm may prefer more incompatibility. However, compatibility has an upside for both firms as it enhances the users' willingness to pay. It is indeed clear that users are better off when compatibility is improved. To see this, note that the consumer surplus is equal to $\frac{1}{2}\left(q_{A}^{*}+q_{B}^{*}\right)^{2}$ and that

$$
q_{A}^{*}+q_{B}^{*}=\frac{2+(1+\gamma) \nu \alpha}{3-(2+\gamma) \nu}, \text { with } \frac{d\left(q_{A}^{*}+q_{B}^{*}\right)}{d \gamma}=\frac{2+(3-\nu) \alpha}{(3-(2+\gamma) \nu)^{2}} \nu>0 .
$$

\subsubsection{Ex ante vs. ex post standardization}

Collecting the previous results, it appears that the small firm (firm $B$ here) unambiguously prefers more compatibility as it reduces its disadvantage with respect to the big firm and it expands demand. As for the big firm (firm $A$ here), more compatibility is a mixed blessing: it expands demand but it attenuates the initial competitive advantage conferred by the installed base. As the latter effect depends on the size of the installed base, we expect the big firm to prefer full compatibility to full incompatibility if the installed base is not too large. We check indeed that

$$
\left.\Pi_{A}^{*}\right|_{\gamma=1} \geq\left.\Pi_{A}^{*}\right|_{\gamma=0} \Leftrightarrow \alpha \leq \frac{1-2 \nu}{3-4 \nu+2 \nu^{2}} \equiv \bar{\alpha} .
$$

Suppose now for simplicity that compatibility is all or nothing and that it has to be agreed upon by the two firms to be achieved (i.e., it is technically or legally impossible to achieve compatibility on a unilateral basis). Then, the previous analysis teaches us that if the installed base of the big firm is not too large (i.e., if $\alpha \leq \bar{\alpha}$ ), both firms will prefer compatibility. For instance, they will agree to adopt the same specifications for their network goods so as to make them fully interoperable. In that case, ex ante (or 'de jure') standardization prevails. Typically, this form of standardization follows from negotiations among firms that take place within Standard-Setting Organizations (SSOs). ${ }^{10}$

In contrast, if the big firm starts the game with a significant installed base (i.e., if $\alpha>\bar{\alpha}$ ), then it will not agree with the small firm to achieve compatibility. Both firms will then push their own specification and let users choose between two incompatible network goods. A so-

\footnotetext{
${ }^{9}$ For values of $\gamma<1 /(2-\nu)$, firm $B$ stays on the market provided that $\alpha \leq(1-(2-\gamma) \nu) /(v(1-(2-\nu) \gamma))$.

${ }^{10}$ There exist a very large number of SSOs, working at different levels: international (e.g., the International Telecommunication Union, ITU), regional (e.g., the European Committee for Standardization, CEN), or sectorial (e.g., the World Wide Web Consortium, W3C).
} 
called 'standards war' will ensue, with both firms fighting to become the ex post (or 'de facto') standard (i.e., the specification that will eventually gain widespread acceptance). ${ }^{11}$

\subsubsection{Strategies in standards wars}

As we have just seen, the existence of a larger installed base for some firm does not only confer a competitive advantage to this firm but may also lead it to prefer incompatibility. If incompatibility is the chosen course of action, one understands then that firms may have an incentive to build an installed base today so as to increase their chances to win the standards war tomorrow. They may thus want to set lower prices today (so as to attract more users) with the hope of being able to set higher prices tomorrow (as users will be willing to pay more to join a larger network).

To analyze this kind of issues, we need to move away from the static framework that we have used so far and adopt instead a dynamic approach, where firms and users make decisions over consecutive periods. Cabral (2011) develops a model of dynamic competition between firms producing incompatible network goods. Users are assumed to live for potentially many periods (i.e., they die and are replaced with a constant hazard rate). As above, users derive stand-alone and network benefits from the network good that they choose. The stand-alone component is received once the user joins a network and its value is supposed to be the user's private information; the network component is received each period that a consumer is still alive. A newborn user chooses one of the two existing networks and stays with it until death. This decision is assumed to be made in a rational, forward looking way. This means that users are able to anticipate all future decisions so as to estimate correctly the evolution of network sizes. In each period, the two firms compete for new consumers to join their network by setting the price of their network good (prices below marginal costs are allowed).

In this framework, a firm with a larger network faces an interesting trade-off when setting its prices: taking a short-term perspective, the big firm should set higher prices as it is more attractive to users ('harvesting' effect); however, when taking future payoffs into account, the firm has an incentive to set lower prices because the gains from increasing network size are larger for a big than for a small firm ('investment' effect). It is a priori not clear which of these effects will dominate, meaning that price functions may be increasing or decreasing in time.

Although the pricing equilibrium is symmetric, market shares are generally asymmetric because of the stochastic appearance of new users. There are then two questions of interest: (i) Does the large network attract a new user with higher probability than the small network? (ii) Does the large network increase its size in expected value? The answer to the first question is yes. As for the second question, the answer is yes as well, as long as network effects are sufficiently strong and the big firm is still shy of holding $100 \%$ of the market.

The previous results suggest that getting a head start may prove valuable in a standards wars. However, the model abstracts away a number of factors that may reverse this statement. First,

\footnotetext{
${ }^{11}$ Well-known standards wars in the consumer electronics sector are the wars of formats for videotape recording (with VHS winning over Betamax) and for high definition optical discs (with Blu-ray discs supplanting HD DVD).
} 
both network goods are assumed to have the same, fixed, intrinsic quality (which is measured by the value that users attach to the stand-alone benefits). This is a simplifying assumption as product qualities result from firms' investments in R\&D and are likely to improve over time (because of knowledge spillovers and/or users' feedback). Firms may then face the following trade-off when deciding to enter early on the market: they may secure a head start but they may also have to compromise on the quality of their product; a later entrant with a better product would then be able to overcome an initial disadvantage.

A second issue concerns compatibility across periods: by posing that users can collect network benefits during their whole life, the model implicitly assumes that new versions of the network goods are backward compatible with old ones. In reality, firms may decide against backward compatibility. One reason is that firms may want to force old users to buy a new version of the network good (because, if they stick to the old version, they will not enjoy network benefits from users of the new, incompatible, version). This form of 'planned obsolescence' is commonplace in consumer electronics markets. ${ }^{12}$ Another reason, which is hard to disentangle from the previous one, is that backward compatibility often constraints firms in their efforts to improve their products; to reach the full potential of technological advancement, they may thus decide to introduce a new version that is incompatible with the previous one. Abandoning backward compatibility clearly modifies the incentives to build an early installed base of users.

Finally, when users are not as fully rational as they are supposed to be in the previous framework, there may exist less costly ways to get a head start than through low introductory prices. If users form their expectations in a non rational way, firms have the potential to influence these expectations in their favor, thereby creating self-fulfilling prophecies: if users are made to believe that a particular firm will win the standards war, then they will adopt the product of that firm, thereby helping it to win the war and confirming the initial beliefs.

\section{Managing network effects on two-sided platforms}

In this section, we turn to platform markets, where intermediaries facilitate the interaction between separate groups of users. To understand how cross-group external effects shape the strategies of intermediaries, we focus first on the decisions of a single intermediary. We then consider competition among intermediaries in the presence of positive cross-group external effects; we do so in two distinct settings: when markets tip (i.e., when all users aggregate on a single platform at equilibrium) and when they do not. We examine next media markets, where one group of users may exert negative cross-group effects on the other. Finally, we explore a number of issues that were abstracted away in teh previous analyses, namely advanced pricing strategies, within-group external effects, and investment issues.

\footnotetext{
${ }^{12}$ Choi (1994) examines this issue in a monopoly framework.
} 


\subsection{Monopoly pricing by a two-sided platform}

Consider a platform that invites two groups of agents, e.g. sellers and buyers, to interact via the platform. Suppose that the platform charges a membership fee $m_{s}$ on the seller side and a membership fee of $m_{b}$ on the buyer side. Thus, the platform's profits are $\Pi=n_{s}\left(m_{s}-c_{s}\right)+$ $n_{b}\left(m_{b}-c_{b}\right)$, where $n_{k}$ is the number of participants on side $k \in\{s, b\}$ and $c_{k}$ is the cost per participant on the respective side. In a two-sided market, participation on at least one side on the market depends on participation on the other side. Thus, in general, demand on one side depends on prices on both sides of the market.

Participants on side $i$ obtain a stand-alone utility of $r_{k}$ (which corresponds to the intrinsic willingness to pay, when participation on the other side is assumed to be nil) plus some utility that depends on the number of participants on the other side. It may also depend on the participation level on the own side (we will address this possibility in Section 4.5.2). Let us postulate a positive cross-group external effect: a participant on side $s$ benefits from more participation on side $b$ and vice versa. For the sake of simplicity, let us, for the moment, assume that this relationship is linear. Thus the gross utility of a participant on side $s$ is $r_{s}+\pi n_{b}$ and of a participant on side $b$ is $r_{b}+u n_{s}$, where $\pi$ and $u$ are the marginal external effect enjoyed by sellers and buyers, respectively.

Participants have heterogeneous outside options; for simplicity, we assume that there is a unit mass on each interval of length 1 in the range $[0, V]$, where $V$ is sufficiently large such that some participants on each side do not participate in the solutions we are going to consider. Hence, all those participant on side $s$ with an outside option of less than $v_{s}=r_{s}+\pi n_{b}-m_{s}$ will pay the membership fee if they expect a participation level of $n_{b}$, and all those participant on side $b$ with an outside option of less than $v_{b}=r_{b}+u n_{s}-m_{b}$ will pay the membership fee if they expect a participation level of $n_{s}$. Hence, since buyers and sellers are uniformly distributed as specified above, we have $n_{s}=v_{s}$ and $n_{b}=v_{b}$. For given membership fees, participants play an anonymous game and we solve for the Nash equilibrium of this game; the expected number of participants on each side has to be equal to the actual number. Hence, we solve the system of two linear equations in two variables, $n_{s}$ and $n_{b}$ and obtain

$$
n_{s}=\frac{r_{s}+\pi s_{b}-m_{s}-\pi m_{b}}{1-\pi u} \text { and } n_{b}=\frac{r_{b}+u s_{s}-m_{b}-u m_{s}}{1-\pi u} .
$$

We assume that $\pi u<1$ (i.e., cross-group external effects are not too strong), so that the numbers of agents registering on the platform are decreasing functions of the membership fees.

We can now solve the platform's maximization problem. The first-order conditions with respect to $m_{s}$ and $m_{b}$ can be written respectively as

$$
\left\{\begin{array}{l}
m_{s}=\frac{1}{2}\left(c_{s}+r_{s}\right)-\frac{1}{2}(\pi+u) m_{b}+\frac{1}{2}\left(\pi r_{b}+u c_{b}\right), \\
m_{b}=\frac{1}{2}\left(c_{b}+r_{b}\right)-\frac{1}{2}(\pi+u) m_{s}+\frac{1}{2}\left(u r_{s}+\pi c_{s}\right) .
\end{array}\right.
$$

We observe that the presence of positive cross-group effects affects the platform's choice of fees in two ways. First, positive cross-group effects generate a negative relationship between the two fees; because participations on the two sides are complementary to one another, lowering 
the fee on one side drives the platform to raise the fee on the other side. ${ }^{13}$ Second, the crossgroup effects make the optimal fee on one side depend also on features (cost, willingness to pay) pertaining to the other side. This is another consequence of the complementarity between the two sides: the opportunity cost of attracting, say, an additional buyer is lower than the marginal cost $\left(c_{b}\right)$ because this additional buyer will entice extra participation on the seller side and hence, extra revenues and costs for the platform on that side (which depend on $r_{s}$ and $c_{s}$ ). In general, because of cross-group effects, revenues and costs cannot be easily allocated to one side or the other.

We can now proceed by solving the previous system to obtain the optimal fees. ${ }^{14}$ To clarify the intuition, we introduce the following notation: let $\mu_{k} \equiv r_{k}-c_{k}$ denote the difference between the intrinsic willingness to pay $\left(r_{k}\right)$ and the marginal cost $\left(c_{k}\right)$ on side $k(k=s, b)$. We can then write:

$$
\left\{\begin{array}{l}
m_{s}^{*}-c_{s}=\frac{1}{2} \mu_{s}+\frac{1}{2} \frac{\pi-u}{4-(u+\pi)^{2}}\left(2 \mu_{b}+(u+\pi) \mu_{s}\right), \\
m_{b}^{*}-c_{b}=\frac{1}{2} \mu_{b}+\frac{1}{2} \frac{u-\pi}{4-(u+\pi)^{2}}\left(2 \mu_{s}+(u+\pi) \mu_{b}\right) .
\end{array}\right.
$$

We have expressed the optimal margins (i.e., the optimal fee minus the marginal cost) as the sum of two terms. The first term is the margin that platforms would set absent cross-group effects (i.e., for $\pi=u=0$ ); in that case, the margin on each side would only depend on costs and willingness to pay on that side (it is as though the 'platform' was selling two independent services to two separate groups of customers). The second term depends on the intensity of the cross-group effects and on parameters pertaining to both sides. Interestingly, in this linear model, this second term vanishes in the special case where the marginal cross-group external effects are equal across sides $(\pi=u)$. In contrast, if $\pi>u$, i.e., if sellers value more the interaction with buyers than buyers value the interaction with sellers, we see that the platform chooses to have a larger margin on the seller side and a lower margin on the buyer side (with respect to what would prevail in the absence of cross-group effects). The intuition is simple: as the two sides are complementary, the platform can attract more agents on one side by lowering its fee on the other side; when, for instance, $\pi>u$, this 'leverage strategy' is more effective when applied on the buyer side; it is thus profitable for the platform to lower the buyer fee and to capture the extra value created on the seller side by increasing the seller fee. This reasoning may even lead the platform to set a negative margin on the buyer side: it can be checked that for $\pi>u$ and $\mu_{b} / \mu_{s}<(\pi-u) /\left(2-\pi(\pi+u)\right.$, we have $m_{b}^{*}<c_{b}$. The exact reverse logic applies in the case where $u>\pi$.

Finally, we compute the platform's profit at the optimum as

$$
\Pi^{*}=\frac{\mu_{s}^{2}+\mu_{b}^{2}+\mu_{s} \mu_{b}(\pi+u)}{4-(\pi+u)^{2}} .
$$

\footnotetext{
${ }^{13}$ In that regard, two-sided platforms bear some resemblance with multiproduct firms. Yet, as Rochet and Tirole (2003) point out, end users internalize the corresponding externalities in a multiproduct setting but not in a multisided setting.

${ }^{14}$ To satisfy the second-order conditions for profit maximization, we need to impose a more stringent condition than $e_{s} e_{b}<1$, namely $\left(e_{s}+e_{b}\right)^{2}<4$.
} 
We see clearly in the latter expression that the platform's profit increases with the intensity of the cross-group external effects (i.e., $u$ and $\pi$ ).

More generally, if the distribution of agents' types is not linear, we obtain increasing and monotone relationships $n_{s}=N_{s}\left(v_{s}\right)$ and $n_{b}=N_{b}\left(v_{b}\right)$, respectively. As illustrated above for the linear case, the platform maximizes $N_{s}\left(v_{s}\right)\left(m_{s}-c_{s}\right)+N_{b}\left(v_{b}\right)\left(m_{b}-c_{b}\right)$ with respect to $m_{s}$ and $m_{b}$, where the participation levels $N_{s}\left(v_{s}\right)$ and $N_{b}\left(v_{b}\right)$ depend on membership fees.

\subsection{Pricing under platform competition when markets tip}

We now examine the competition between two platforms, which we note by 1 and 2 . We continue to consider two groups of agents, which we continue to call, for convenience, sellers (group $s$ ) and buyers (group $b$ ). We focus here on situations where only one platform survives at equilibrium; it is then said that the market 'tips' in the sense that all agents end up interacting on a single platform. Ingredients for such a result are positive and strong cross-group effects, closely substitutable platforms, and singlehoming.

In the model we develop, adapted from Caillaud and Jullien (2003), the platforms offer exactly the same services and are thus seen, other things being equal, as perfect substitutes by the agents. Both groups, sellers and buyers, are supposed to consist of a continuum of mass one. There exist positive cross-group external effects between the two groups insofar as each agent uses the matching services of one or the other platform to find the unique trading partner whom she has in the other group. Hence, the probability to find one's partner on a particular platform increases with the number of agents of the other group that register with this platform. In particular, if $n_{s}^{i}$ sellers (resp. $n_{b}^{i}$ buyers) register with platform $i(i=1,2)$, then the probability for a buyer (resp. a seller) to find her match on platform $i$ is equal to $\lambda n_{s}^{i}$ (resp. $\lambda n_{b}^{i}$ ) where $\lambda$ is the probability that two matching partners find each other when they register with the same platform. The gross gain from a successful match is equal to $1 / 2$ for each agent (gains of trade are normalized to one and are supposed to be equally shared among trading partners after some efficient bargaining process). The net gain is then $1 / 2\left(1-p^{i}\right)$, where $p^{i}$ is the transaction fee that platform $i$ charges. ${ }^{15}$ Given that platforms also set membership fees $m_{k}^{i}$, the expected utilities for a seller and for a buyer when registering with platform $i$ along with $n_{s}^{i}$ sellers and $n_{b}^{i}$ buyers are respectively equal to $U_{s}^{i}=\lambda n_{b}^{i} \frac{1}{2}\left(1-p^{i}\right)-m_{s}^{i}$ and $U_{b}^{i}=\lambda n_{s}^{i} \frac{1}{2}\left(1-p^{i}\right)-m_{b}^{i}$.

We analyze the following game. In the first stage, platforms set their price structure to maximize their profit; that is, platform $i$ chooses the triple $\left(m_{s}^{i}, m_{b}^{i}, p^{i}\right)$ to maximize $\Pi^{i}=$ $n_{s}^{i}\left(m_{s}^{i}-c_{s}\right)+n_{b}^{i}\left(m_{b}^{i}-c_{b}\right)+\lambda n_{s}^{i} n_{b}^{i} p^{i}$, where $c_{k}(k=s, b)$ is the constant cost a platform incurs when providing services to one agent of type $k$ (with $c_{s}+c_{b}<\lambda$ so that total gains from trade are larger than total costs). In the second stage, agents choose which platform (if any) to register with; we assume singlehoming on both sides (agents register with at most one platform) and we normalize the outside option to zero.

\footnotetext{
${ }^{15}$ Because we assume constant gains from trade and efficient bargaining, transaction fees are non-distortionary. As a result, it is only the total fee that matters (i.e., $p^{i}$ ) and not the way it is split between the trading partners.
} 
In this Bertrand competition, platforms resort to a 'divide-and-conquer' strategy, which consists in first in 'dividing' by subsidizing one group of agents to convince them to join and next, in 'conquering' the agents of the other group, who have no better option than to join the platform as well. To be sure of attracting the group of, say, buyers, platform $i$ must offer them a better deal than platform $j$, even in the worst-case scenario where buyers hold the pessimistic belief that they will find no seller on platform $i$; that is, it must be that $-m_{b}^{i}>\lambda \frac{1}{2}\left(1-p^{j}\right)-m_{b}^{j}$. If this condition is met, buyers will join platform $i$ and sellers will follow suit (whatever their beliefs), thereby generating maximal aggregate surplus $\lambda-c_{s}-c_{b}$, which platform $i$ can capture by setting the transaction fee at its maximal level $\left(p^{i}=1\right)$. Platform $i$ finds this strategy profitable as long as $\lambda-c_{s}-c_{b}+m_{s}^{i} \geq-m_{b}^{i}$. Yet, as platform $j$ can act in exactly the same way, competition through divide-an-conquer strategies will drive profits to zero and allow only one platform to remain active. At equilibrium, the remaining platform subsidizes full participation, charges the maximal transaction fee $\left(p^{i}=1\right)$ and makes zero profit $\left(m_{s}^{i}+m_{b}^{i}=c_{s}+c_{b}-\lambda\right)$. As the presence of positive cross-side external effects makes it efficient to have all agents register with the same platform, the equilibrium is socially desirable.

If one platform (the incumbent) could play before the other (the entrant), the same equilibrium would prevail, with the incumbent deterring the entry but foregoing all profit. The surviving platforms may, however, achieve positive profits at equilibrium when transaction fees are not feasible (e.g., because agents, when matched, could bypass the platform to trade). ${ }^{16}$

\subsection{Pricing under platform competition when markets do not tip}

We now introduce some differentiation between the platforms, so as to add a 'dispersion' force that can counterbalance the 'agglomeration' force exerted by the combination of the positive cross-group effects. We also explicitly consider the possibility for the members of one group to be active on two platforms at the same time (so-called multihoming). To this end, we follow the approach proposed by Armstrong (2006) and Armstrong and Wright (2007).

\subsubsection{Two-sided singlehoming}

The basic ingredients are the same as in the model with two competing matching intermediaries: a unit mass of sellers and a unit mass of buyers having to choose at most one platform on which they will interact, with this interaction generating positive cross-group external effects. In contrast with the previous model, we assume now that platforms only compete in membership fees and that agents perceive them as horizontally differentiated. Horizontal differentiation is modeled in the Hotelling fashion: platforms are located at the extreme points of the unit interval; sellers and buyers are uniformly distributed on this unit interval and incur an opportunity cost of visiting a platform that increases linearly in distance at rates $\tau_{s}$ and $\tau_{b}$, respectively; participation is sufficiently attractive to drive all buyers and sellers to be active on one platform

\footnotetext{
${ }^{16}$ See Caillaud and Jullien $(2001,2003)$.
} 
(it follows that on each side, the total number of agents on the two platforms adds up to 1: $\left.n_{s}^{1}+n_{s}^{2}=n_{b}^{1}+n_{b}^{2}=1\right)$.

The nature of the interaction on the platform is the following: sellers offer perfectly differentiated products and buyers purchase one unit from each seller active on the platform; each seller makes a profit per buyer of $\pi$ and each buyer derives utility $u$ per seller. ${ }^{17}$ Hence, seller and buyer surpluses gross of any opportunity cost of visiting platform $i$ are

$$
v_{s}^{i}=r_{s}+n_{b}^{i} \pi-m_{s}^{i} \quad \text { and } \quad v_{b}^{i}=r_{b}+n_{s}^{i} u-m_{b}^{i}
$$

where $m_{b}^{i}$ and $m_{s}^{i}$ are the membership fees set by platform $i$, and $r_{b}$ and $r_{s}$ are the stand-alone benefits. The seller and the buyer who are indifferent between the two platforms are respectively located at $x_{s}$ and $x_{b}$ such that $v_{s}^{1}-\tau_{s} x_{s}=v_{s}^{2}-\tau_{s}\left(1-x_{s}\right)$ and $v_{b}^{1}-\tau_{b} x_{b}=v_{b}^{2}-\tau_{b}\left(1-x_{b}\right)$. It follows that $n_{s}^{1}=x_{s}, n_{s}^{2}=1-x_{s}, n_{b}^{1}=x_{b}$, and $n_{b}^{2}=1-x_{b}$. Combining these equations together with the expressions of $v_{s}^{i}$ and $v_{b}^{i}$, we obtain the following expressions for the numbers of buyers and sellers at the two platforms:

$$
\left\{\begin{array}{l}
n_{s}^{i}\left(n_{b}^{i}\right)=\frac{1}{2}+\frac{1}{2 \tau_{s}}\left(\left(2 n_{b}^{i}-1\right) \pi-\left(m_{s}^{i}-m_{s}^{j}\right)\right), \\
n_{b}^{i}\left(n_{s}^{i}\right)=\frac{1}{2}+\frac{1}{2 \tau_{b}}\left(\left(2 n_{s}^{i}-1\right) u-\left(m_{b}^{i}-m_{b}^{j}\right)\right) .
\end{array}\right.
$$

Solving the previous system, we derive the number of buyers and sellers as a function of the membership fees:

$$
\begin{aligned}
& n_{s}^{i}\left(m_{s}^{i}, m_{s}^{j}, m_{b}^{i}, m_{b}^{j}\right)=\frac{1}{2}+\frac{\pi\left(m_{b}^{j}-m_{b}^{i}\right)+\tau_{b}\left(m_{s}^{j}-m_{s}^{i}\right)}{2\left(\tau_{b} \tau_{s}-u \pi\right)} \\
& n_{b}^{i}\left(m_{s}^{i}, m_{s}^{j}, m_{b}^{i}, m_{b}^{j}\right)=\frac{1}{2}+\frac{u\left(m_{s}^{j}-m_{s}^{i}\right)+\tau_{s}\left(m_{b}^{j}-m_{b}^{i}\right)}{2\left(\tau_{b} \tau_{s}-u \pi\right)}
\end{aligned}
$$

where we assume that $\tau_{b} \tau_{s}>u \pi$, i.e., that the transportation cost parameters $\tau_{b}$ and $\tau_{s}$ (which measure the perceived horizontal differentiation between the two platforms) are sufficiently large with respect to the gains from trade $u$ and $\pi$ (which measure the cross-group external effects). Under this assumption, the number of members of one group at one platform decreases not only with the membership fee that they have to pay but also with the membership fee that the other group has to pay on this platform. ${ }^{18}$

Platform $i$ chooses $m_{s}^{i}$ and $m_{b}^{i}$ to maximize $\Pi^{i}=\left(m_{s}^{i}-c_{s}\right) n_{s}^{i}(\cdot)+\left(m_{b}^{i}-c_{b}\right) n_{b}^{i}(\cdot)$, where we assume as before that platforms incur $\operatorname{costs} c_{s}$ and $c_{b}$ when they register additional sellers and buyers. At the symmetric equilibrium $\left(m_{s}^{1}=m_{s}^{2} \equiv m_{s}\right.$ and $\left.m_{b}^{1}=m_{b}^{2} \equiv m_{b}\right)$, the first-order conditions can be written as ${ }^{19}$

$$
\left\{\begin{array}{l}
m_{s}=c_{s}+\tau_{s}-\frac{u}{\tau_{b}}\left(\pi+m_{b}-c_{b}\right), \\
m_{b}=c_{b}+\tau_{b}-\frac{\pi}{\tau_{s}}\left(u+m_{s}-c_{s}\right) .
\end{array}\right.
$$

\footnotetext{
${ }^{17}$ It is assumed, quite realistically, that in a seller-buyer relationship, prices or terms of transaction are independent of the membership fee that applies to buyers and sellers.

${ }^{18}$ For stronger cross-group external effects and/or weaker horizontal differentiation (i.e., for $u \pi>\tau_{b} \tau_{s}$ ), the number of agents on one platform would be an increasing function of their membership fee. The market would then naturally tip as in the model of the previous section.

${ }^{19}$ The second-order conditions require $4 \tau_{s} \tau_{b}>(u+\pi)^{2}$, which is a more restrictive condition than $\tau_{b} \tau_{s}>u \pi$.
} 
The equilibrium membership fee for the sellers is equal to marginal costs plus the productdifferentiation term as in the standard Hotelling model, adjusted downward by the term $\frac{u}{\tau_{b}}(\pi+$ $\left.m_{b}-c_{b}\right)$. To understand this term, note from expression (1) that each additional seller attracts $u / \tau_{b}$ additional buyers. These additional buyers allow the intermediary to extract $\pi$ per seller without affecting the sellers' surplus. In addition, each of the additional $u / \tau_{b}$ buyers generates a margin of $m_{b}-c_{b}$ to the platform. Thus $\frac{u}{\tau_{b}}\left(\pi+m_{b}-c_{b}\right)$ represents the value of an additional buyer to the platform. The same holds on the buyers' side.

Solving the system of first-order conditions gives explicit expressions for equilibrium membership fees and platforms' profits: ${ }^{20}$

$$
\begin{aligned}
m_{s}^{*} & =c_{s}+\tau_{s}-u \text { and } m_{b}^{*}=c_{b}+\tau_{b}-\pi, \\
\Pi^{1 *} & =\Pi^{2 *}=\frac{1}{2}\left(\tau_{b}+\tau_{s}-u-\pi\right) .
\end{aligned}
$$

We observe that the equilibrium membership fee for one group is equal to the usual Hotelling formulation (marginal cost plus transportation cost) adjusted downward by the cross-group external effect that this group exerts on the other group. As for the platforms' equilibrium profits, they are increasing in the degree of product differentiation on both sides of the market (as in the Hotelling model) and decreasing in the buyers' and sellers' surplus for each transaction, i.e., the magnitude of the cross-group external effects. The intuition for the latter result is the following: as cross-group external effects increase, platforms compete more fiercely to attract additional agents on each side as they become more valuable.

\subsubsection{Multihoming on one side (competitive bottlenecks)}

Suppose now that sellers have the possibility to multihome (i.e., to be active on both platforms at the same time), while buyers continue to singlehome. Sellers are then divided into three subintervals on the unit line: those sellers located "on the left" register with platform 1 only, those located "around the middle" register with both platforms, and those located "on the right" register with platform 2 only. At the boundaries between these intervals, we find the sellers who are indifferent between visiting platform 1 (resp. 2) and not visiting any platform; their locations are found as, respectively, $x_{10}$ such that $r_{s}+n_{b}^{1} \pi-m_{s}^{1}=\tau_{s} x_{10}$, and $x_{20}$ such that $r_{s}+n_{b}^{2} \pi-m_{s}^{2}=\tau_{s}\left(1-x_{20}\right)$. We assume for now that $0<x_{20}<x_{10}<1$ (we provide necessary and sufficient conditions below), so that $n_{s}^{1}=x_{10}$ and $n_{s}^{2}=1-x_{20}$, with the multihoming sellers being located between $x_{20}$ and $x_{10}$. As far as buyers are concerned, we have the same situation as before. The number of buyers and sellers visiting each platform are thus respectively given by

$$
n_{b}^{i}=\frac{1}{2}+\frac{u\left(n_{s}^{i}-n_{s}^{j}\right)-\left(m_{b}^{i}-m_{b}^{j}\right)}{2 \tau_{b}} \text { and } n_{s}^{i}=\frac{r_{s}+n_{b}^{i} \pi-m_{s}^{i}}{\tau_{s}} .
$$

\footnotetext{
${ }^{20}$ We assume that $r_{b}+u / 2+\pi>c_{b}+\tau_{b}$ and $r_{s}+\pi / 2+u>c_{s}+\tau_{s}$ to guarantee full participation on the two sides.
} 
Solving this system of four equations in four unknowns, we get

$$
\left\{\begin{array}{l}
n_{b}^{i}=\frac{1}{2}+\frac{u\left(m_{s}^{j}-m_{s}^{i}\right)+\tau_{s}\left(m_{b}^{j}-m_{b}^{i}\right)}{2\left(\tau_{b} \tau_{s}-u \pi\right)} \\
n_{s}^{i}=\frac{\pi}{\tau_{s}}\left(\frac{1}{2}+\frac{u\left(m_{s}^{j}-m_{s}^{i}\right)+\tau_{s}\left(m_{b}^{j}-m_{b}^{i}\right)}{2\left(\tau_{b} \tau_{s}-u \pi\right)}\right)+\frac{r_{s}-m_{s}^{i}}{\tau_{s}} .
\end{array}\right.
$$

The maximization problems of the two platforms are the same as above. Platform 1's best responses are implicitly defined by the first-order conditions, which can be expressed as

$$
\begin{aligned}
& m_{b}^{1}=\frac{-(u+\pi) m_{s}^{1}+u m_{s}^{2}+\tau_{s} m_{b}^{2}-\pi\left(u-c_{s}\right)+\tau_{s}\left(\tau_{b}+c_{b}\right)}{2 \tau_{s}}, \\
& m_{s}^{1}=\frac{-(u+\pi) \tau_{s} m_{b}^{1}+u \pi m_{s}^{2}+\pi \tau_{s} m_{b}^{2}-\pi u\left(\pi+c_{s}+2 r_{s}\right)+u \tau_{s} c_{b}+\left(\pi+2 c_{s}+2 r_{s}\right) \tau_{b} \tau_{s}}{2\left(2 \tau_{b} \tau_{s}-u \pi\right)} .
\end{aligned}
$$

Second-order conditions require that $8 \tau_{b} \tau_{s}>\pi^{2}+u^{2}+6 \pi u$. This condition is also sufficient to have a unique and stable interior equilibrium. Solving the previous system of equations, we find the equilibrium membership fees:

$$
\begin{aligned}
m_{b}^{*} & \equiv m_{b}^{1 *}=m_{b}^{2 *}=c_{b}+\tau_{b}-\frac{\pi}{4 \tau_{s}}\left(\pi+3 u+2 r_{s}-2 c_{s}\right), \\
m_{s}^{*} & \equiv m_{s}^{1 *}=m_{s}^{2 *}=\frac{1}{2}\left(r_{s}+c_{s}\right)+\frac{1}{4}(\pi-u) .
\end{aligned}
$$

On the seller side, platforms have monopoly power. If the platform focused only on sellers, it would charge a monopoly price equal to $\left(r_{s}+c_{s}\right) / 2+\pi / 4$ (assuming that each seller would have access to half of the buyers and, therefore, would have a gross willingness to pay equal to $\pi / 2$ ). We observe that this price is adjusted downward by $u / 4$ when the cross-group effect that sellers exert on the buyer side is taken into account. Similarly, on the buyer side, platforms charge the Hotelling price, $c_{b}+\tau_{b}$, less a term that depends on the size of the cross-group effects and on the parameters characterizing the seller side $\left(r_{s}, c_{s}\right.$, and $\left.\tau_{s}\right)$.

It is useful to compare price changes in the competitive bottleneck model to those in the two-sided singlehoming model. In equilibrium, we observe that the membership fee for sellers is increasing in the strength of the cross-group effect $\left(\partial m_{s}^{*} / \partial \pi>0\right)$, whereas it is constant in the two-sided singlehoming model. This is due to the monopoly pricing feature on the multihoming side. Everything else equal, if sellers are multihoming, the platform operators directly appropriate part of the rent generated on the multihoming side by setting higher membership fees. This is not the case in the singlehoming world, where the membership fee does not react to the strength of the network effect on the same side since platforms compete for sellers (and buyers).

It follows that at equilibrium,

$$
n_{b}^{1 *}=n_{b}^{2 *}=\frac{1}{2} \text { and } n_{s}^{1 *}=n_{s}^{2 *}=\frac{1}{4 \tau_{s}}\left(u+\pi+2\left(r_{s}-c_{s}\right)\right) .
$$

We still need to check under which conditions some (but not all) sellers multihome at equilibrium. This is so provided that $1 / 2<n_{s}^{i *}<1$, which is equivalent to $2 \tau_{s}<\pi+u+2\left(r_{s}-c_{s}\right)<$ 
$4 \tau_{s}$. Under these conditions, the equilibrium net surplus of sellers and buyers (gross of transportation cost and for one platform) are equal to:

$$
\begin{aligned}
& v_{s}^{*}=\frac{1}{4}(u+\pi)+\frac{1}{2}\left(r_{s}-c_{s}\right), \\
& v_{b}^{*}=\frac{1}{4 \tau_{s}}\left(u^{2}+4 \pi u+\pi^{2}+2(u+\pi)\left(r_{s}-c_{s}\right)\right)+r_{b}-\tau_{b}-c_{b} .
\end{aligned}
$$

Note that $v_{s}^{*}$ is the per platform seller's surplus. ${ }^{21}$ We observe that $v_{s}^{*}$ and $v_{b}^{*}$ are increasing in the net gain of the other side and in the net gain of the own side. The intermediaries' equilibrium profits are

$$
\Pi^{i *}=\frac{1}{16 \tau_{s}}\left(8 \tau_{b} \tau_{s}-\left(\pi^{2}+u^{2}+6 \pi u\right)+4\left(r_{s}-c_{s}\right)^{2}\right)>0 .
$$

\subsubsection{Singlehoming vs. multihoming environments}

How do sellers and buyers surpluses compare in the two environments? ${ }^{22}$ In the model in which sellers multihome, platforms hold an exclusive access to their set of singlehoming buyers (the 'bottleneck'), which makes buyers valuable to extract profits on the seller side. We expect thus platforms to compete fiercely for buyers and, in return, to milk sellers. Hence, we may expect lower prices on the buyer side and higher prices on the seller side when compared to the two-sided singlehoming model. We call this the 'bottleneck effect'. However, this view can be challenged, as under multihoming with $n_{s}^{i *}>1 / 2$, there are more sellers active on a platform than under singlehoming, thus addings value to participation on the buyer side. We call this the 'expansion effect'. Moreover, multihoming sellers have access to all buyers (but pay twice the prices and the transportation costs).

As we illustrate next, whether buyers and sellers prefer one or the other environment depends on the parameter values. Using superscripts $C$ and $S$ to represent the competitive bottleneck and two-sided singlehoming models, we can write the differences in surplus between the two environments as follows. For buyers, we have $v_{b}^{C}-v_{b}^{S}=\left(n_{s}^{C}-\frac{1}{2}\right) u-\left(m_{b}^{C}-m_{b}^{S}\right)$; for singlehoming sellers, we have $v_{s}^{C}-v_{s}^{S}=m_{s}^{S}-m_{s}^{C}$; as for multihoming sellers, we focus on the one located at the middle of the Hotelling line for whom the surplus difference is equal to $2 v_{s}^{C}-\tau_{s}-\left(v_{s}^{S}-\frac{1}{2} \tau_{s}\right)$. Developing the latter expression, we find that this seller is better off in the competitive bottleneck environment than in the singlehoming environment if and only if $\tau_{s}>u$.

Comparing prices, we see that the bottleneck effect dominates if

$$
\begin{aligned}
& m_{s}^{C}>m_{s}^{S} \Leftrightarrow \frac{1}{2}\left(r_{s}+c_{s}\right)+\frac{1}{4}(\pi-u)>c_{s}+\tau_{s}-u, \\
& m_{b}^{C}<m_{b}^{S} \Leftrightarrow c_{b}+\tau_{b}-\frac{\pi}{4 \tau_{s}}\left(3 u+\pi+2 r_{s}-2 c_{s}\right)<c_{b}+\tau_{b}-\pi .
\end{aligned}
$$

Simple computations show that the two conditions are equivalent and boil down to $K>4 \tau_{s}-2 u$, with $K \equiv \pi+u+2\left(r_{s}-c_{s}\right)$. We recall from the analysis of the competitive bottleneck model that

\footnotetext{
${ }^{21}$ Sellers located between $1-n_{s}^{i *}$ and $n_{s}^{i *}$ multihome and, therefore, earn a surplus of $2 v_{s}^{*}$. On the other hand, $v_{s}^{*}$ is the surplus earned by the sellers located between 0 and $1-n_{s}^{i *}$, who choose to visit platform 1 only, and by the sellers located between $n_{s}^{i *}$ and 1 , who choose to visit platform 2 only.

${ }^{22}$ This subsection closesly follows Belleflamme and Peitz (2016).
} 
the following conditions are necessary for some (but not all) sellers to multihome: $2 \tau_{s}<K<4 \tau_{s}$. Note that $4 \tau_{s}-2 u<2 \tau_{s}$ whenever $\tau_{s}<u$.

We can thus distinguish between two cases. First, if $\tau_{s}<u$, it is always true that sellers pay higher and buyers lower fees in the model where sellers multihome than in the model where they singlehome (the bottleneck effect dominates the expansion effect). It follows that buyers are better off in the multihoming environment (as they benefit not only from larger seller participation but also from lower fees), while sellers who singlehome in both environments are worse off (as they pay higher fees for the same buyer participation); as for sellers who would multihome in the competitive bottleneck environment, we have shown above that they prefer the singlehoming environment when $\tau_{s}<u$. So, in this case, buyers and sellers have diverging preferences regarding multihoming: sellers would prefer to be constrained to singlehome, while buyers would prefer that sellers were allowed to multihome.

Second, if $\tau_{s}>u$, we can find parameter values for which all agents are better off in the competitive bottleneck environments. We already know that this is true for multihoming sellers (whatever the value of $K$ ). It is also true for singlehoming sellers if $2 \tau_{s}<K<4 \tau_{s}-2 u$ (as they pay lower fees in this case). Yet, in this region of parameters, buyers pay higher fees; the benefit of interacting with more sellers must then be sufficiently large to have $v_{b}^{C}>v_{b}^{S}$; this is so if $K>2\left((2 \pi+u) \tau_{s}-\pi u\right) /(\pi+u) \equiv K_{0}$, with $K_{0}<4 \tau_{s}-2 u$ when $\tau_{s}>u$. In sum, if $\tau_{s}>u$ and $2 \tau_{s}<K<K_{0}$, then both groups prefer the situation where sellers are allowed to multihome.

We can conclude that without further information, we cannot decide whether allowing multihoming on one side (with the other side singlehoming) leads to higher or lower net surpluses on either side. It is therefore a priori not possible to say whether the side that changes its behavior from singlehoming to multihoming (or reverse) benefits or suffers from this change of behavior.

\subsection{Media markets}

Media platforms are just one application of two-sided platforms where readers or viewers constitute one group and advertisers the other. A feature of most media platforms is that cross-group external effects go in opposite directions: while advertisers prefer a platform with more viewers, everything else given, the reverse holds true for viewers, as they dislike a platform that carries a lot of advertising. Thus, advertising is a nuisance. Many media platforms use a one-sided revenue model: they charge advertisers for posting ads and give away content bundled with advertising for free to viewers. This applies to free-to-air television, radio broadcasting and many media platforms on the internet.

According to the baseline media model developed by Anderson and Coate (2005), two media platforms compete for viewers. While viewers are assumed to singlehome, advertisers can post ads on multiple platforms. The key difference to the previous analysis is that media platforms are purely advertising-financed. In particular, they are assumed to fix the advertising space or, 
equivalently, set the ad price per viewer. ${ }^{23}$

Here, we review the basics of the competitive bottleneck model with $n$ media platforms. Each media platform $i$ provides program content to attract viewers and delivers these eyeballs to advertisers. ${ }^{24}$ Advertising revenue is the sole source of finance to platforms, and advertisers are assumed to be price takers. Platform $i$ 's profit is thus $\Pi^{i}=P^{i} a^{i}, i=1, \ldots n$, where $P^{i}$ is the price per ad and $a^{i}$ is the number of ads posted.

Content is attractive to viewers, but viewers consider the embodied ads to be a nuisance. Viewers' tastes over platform content is differentiated. Each viewer is assumed to singlehome, i.e., she makes a discrete choice over which platform to visit. Denote by $n_{b}^{i}\left(a^{i}, \mathbf{a}^{-i}\right)$ the number of viewers (demand) for platform $i$ as a function of its own ad level and the vector of ad levels, $\mathbf{a}^{-i}$, of its competitors.

On the advertiser side, all ads on a platform are seen by the viewers. Advertisers have different willingness to pay for reaching viewers (impressions). Assume that the advertiser's willingness-to-pay for advertising on each platform is a linear function of the number of viewers on the platform. In other words, there are constant returns to reaching prospective customers. This allows us to rank advertisers in terms of decreasing willingness to pay per eyeball, from large to small, giving a downward-sloping function $p(\cdot)$. When platform $i$ opens $a^{i}$ slots for advertising, the price per ad per viewer is $p\left(a^{i}\right)$, so that the price per ad is $P^{i}=p\left(a^{i}\right) n_{b}^{i}\left(a^{i}, \mathbf{a}^{-i}\right)$. Hence, under these assumptions, we can write

$$
\pi_{i}=a^{i} p\left(a^{i}\right) n_{b}^{i}\left(a^{i}, \mathbf{a}^{-i}\right)=R\left(a^{i}\right) n_{b}^{i}\left(a^{i}, \mathbf{a}^{-i}\right),
$$

where $R\left(a^{i}\right)$ is the revenue per ad per viewer. The first-order condition (with ad levels as the strategic variables) is written as

$$
\frac{R^{\prime}\left(a^{i}\right)}{R\left(a^{i}\right)}=\frac{-\partial_{1} n_{b}^{i}\left(a^{i}, \mathbf{a}^{-i}\right)}{n_{b}^{i}\left(a^{i}, \mathbf{a}^{-i}\right)}
$$

where $\partial_{1}$ is the partial dervative with respect to the first argument. This equations says that the elasticity of revenue per viewer should equal the viewer demand elasticity. This expression relates to the standard elasticity condition for oligopoly pricing. ${ }^{25}$ The left-hand side, $R^{\prime}(a) / R(a)$, is decreasing in $a$ under the condition that $R(a)$ is log-concave. Hence, from (2), lower ad levels result whenever the equilibrium value of $-\partial_{1} n_{b}^{i}\left(a^{i}, \mathbf{a}^{-i}\right) / n_{b}^{i}\left(a^{i}, \mathbf{a}^{-i}\right)$ increases in a change in market structure.

\footnotetext{
${ }^{23}$ This may approximate business practice. A standard practice in media markets is to report the CPM (cost per thousand impressions) based on past experience. Advertisers are then compensated if actual participation deviates from past participation.

${ }^{24}$ Our exposition follows Anderson, Foros, Kind, and Peitz (2012). For a general treatment see Anderson and Peitz (2015).

${ }^{25}$ Indeed, consider the (Bertrand) oligopoly problem of $\max _{p_{i}} \pi_{i}=\left(p_{i}-c_{i}\right) n^{i}\left(p_{i}, \mathbf{p}_{-i}\right)$ where now $n^{i}\left(p_{i}, \mathbf{p}_{-i}\right)$ is the demand addressed to firm $i$ and $p_{i}$ is the price $i$ sets for its product, while $c_{i}$ is its marginal cost (and $\mathbf{p}_{-i}$ is the vector of other firms' prices). Then the first-order condition can be written as $\frac{1}{\left(p_{i}-c_{i}\right)}=\frac{-N_{i}^{\prime}\left(p_{i}, \mathbf{p}_{-i}\right)}{N_{i}\left(p_{i}, \mathbf{p}_{-i}\right)}$ which, in elasticity form, gives the inverse elasticity (Lerner) rule for pricing.
} 
Consider the effects of platform entry at a symmetric equilibrium. For example, in the case of the Salop circle model, the right-hand side takes the value $n / \tau$, where the transport parameter $\tau$ measures how strongly platform content is differentiated. In the standard oligopoly context with product differentiation, this means simply that increasing the number of competitors leads to lower prices. In the present media economics context, this means that entry of a media platform leads to lower equilibrium ad levels. Competition for viewers plays out as competition in nuisance levels, and more competition leads to a lower nuisance level. For advertisers, the lower level of ads implies a higher ad price per viewer.

While the prediction of entry (and, relatedly, mergers) are unambiguous in this competitive bottleneck model, their empirical relevance may be questioned. Indeed, as Anderson, Foros, Kind, and Peitz (2012) mention, at least two alternative mechanisms can overturn the result that entry reduces ad levels and that a merger increases ad levels. A countervailing effect arises when viewers spend some time on various media platforms and have limited attention for advertising they are exposed to. This introduces strategic interaction among platforms on the advertiser side. The attention of viewers becomes a common property resource that platforms tend to overexploit. A larger platform has stronger incentives to internalize the associated external effect on other ads and, therefore, opens fewer ad slots than a smaller platform. With symmetric platforms, the entry of a platform tends to lead to higher ad levels, as the negative effect of additional ads on existing advertisers is felt less strongly by each platform. ${ }^{26}$

An alternative explanation that entry can lead to higher ad levels (and a merger to lower ad levels) rests purely on the effects of viewer multihoming on the exposure of viewers to ads. To the extent that a single impression is all that an advertiser cares about, advertising on multiple media carries the risk of wasting impressions because some viewers will be treated twice. This has implications for the advertising strategy of media platforms (as well as the decision on content of platforms).

Ambrus, Calvano, and Reisinger (2016) consider a setting with viewers who can multihome and homogeneous advertisers who can post multiple ads. ${ }^{27}$ Start with a monopoly setting and suppose that a second platform enters. There are two effects due to entry. First, there is a duplication effect: as each multihoming consumer can now get informed about an advertiser's product on both platforms, the single ad is worth less. Due to the duplication effect, the advertising intensity tends to fall in duopoly. However, there is a countervailing effect, which can be called the business-sharing effect. In monopoly, all consumers are exclusive consumers. By contrast, in duopoly, some of the lost business due to increased advertising levels comes from consumers active on both platforms. Here, the duopolist shares business with its rival. Losing these consumers is less detrimental than losing exclusive consumers. Due to this businesssharing effect, a duopolist tends to have a greater incentive to increase the advertising level than a monopolist. The business-sharing effect possibly dominates the duplication effect, in which

\footnotetext{
${ }^{26}$ For a formal analysis of media markets with limited viewer attention for ads, see Anderson and Peitz (2016).

${ }^{27}$ For a related contribution, see Anderson, Foros, and Kind (2015). For an overview of the effects of viewer multihoming in media markets, see Peitz and Reisinger (2015).
} 
case advertising levels in duopoly are larger than in monopoly.

\subsection{Further issues}

The focus of our presentation in this section has been to determine features of the equilibrium allocation of markets in which one or multiple platforms enable the interaction between two groups of users restricting the analysis to stylized and simple settings. Here, we look at, in some sense, richer settings: (i) richer price instruments by the platform, (ii) within-group external effects and, in particular, competition among sellers, and (iii) investment incentives by sellers and platforms.

\subsubsection{Price instruments}

In most of the analysis we postulated that platforms charge listing or access fees to the platform. However, pricing strategies may be more involved. In particular, platforms may choose two-part tariffs or offer some insurance against unexpected drops in participation on the other side.

Two-part tariffs. Reisinger (2014) allows platforms to set two-part tariffs, adding a usage (or per-transaction) fee to the membership (or subscription) fee that we considered so far. It is indeed not rare that platforms charge two-part tariffs to at least one of the sides. For instance, in software platforms, developers are charged a fixed fee for getting access to source code of the system and, in addition, pay royalties for the applications they sell to users. What are the implications of this form of price discrimination on the profits of competing platforms and on the welfare of the two sides?

The model is modified as follows. The seller and buyer surpluses gross of any opportunity cost of visiting a platform become

$$
v_{s}^{i}=n_{b}^{i}\left(\pi-t_{s}^{i}\right)-m_{s}^{i} \quad \text { and } \quad v_{b}^{i}=n_{s}^{i}\left(u-t_{b}^{i}\right)-m_{b}^{i},
$$

where $t_{k}^{i}$ is the transaction (usage) fee that platform $i$ charges on side $k$. As for platform $i$ 's profit, it is now expressed as

$$
\Pi^{i}=\left(m_{s}^{i}-c_{s}\right) n_{s}^{i}+\left(m_{b}^{i}-c_{b}\right) n_{b}^{i}+\left(t_{s}^{i}+t_{b}^{i}-\gamma\right) n_{s}^{i} n_{b}^{i},
$$

where $\gamma$ is the constant per-transaction cost incurred by the platform. The game is the same as before, except that platforms now have four strategic variables to choose.

A general result that emerges is that a continuum of equilibria exists when platforms compete using two-part tariffs. ${ }^{28}$ The reason behind this multiplicity is that platforms only care about the total price that agents pay but not about how it splits between the membership and the transaction fees (i.e., different combinations of the two fees yield the same profit); as a result, platforms have a continuum of best responses to their rival's tariff. For instance, in the two-sided singlehoming game, the continuum of symmetric equilibria is characterized by platforms charging

\footnotetext{
${ }^{28}$ This was already pointed out by Armstrong (2006).
} 
$T_{k}=m_{k}+t_{k} n_{k}(k=s, b)$, where $m_{s}=c_{s}+\tau_{s}-u+\frac{1}{2}\left(t_{b}-t_{s}\right), m_{b}=c_{b}+\tau_{b}-\pi+\frac{1}{2}\left(t_{s}-t_{b}\right)$ and $0 \leq m_{s} \leq 2 \pi, 0 \leq m_{b} \leq 2 u$. The platforms' equilibrium profits are given by $\Pi=$ $\frac{1}{2}\left(\tau_{s}+\tau_{b}-\pi-u\right)+\frac{1}{4}\left(t_{s}+t_{b}\right)$.

As the previous expressions clearly show, these equilibria lead to different profits for platforms and different surpluses for agents. An unwelcome consequence is that the models (with two-sided singlehoming or with competitive bottlenecks) are deprived of any predictive power.

To solve this problem, Reisinger (2014) allows for heterogeneous trading behavior among agents on both sides. In particular, there exist two types of agents on each side: the 'normal' agents interact with all agents on the other side (as was assumed so far), while the 'small' agents only interact with a fraction of the agents on the other side (or interact with each of them only with some probability); it is further assumed that the small agents are a minority and that platforms are unable to price discriminate across types. In the competitive bottlenecks model where sellers can multihome while buyers cannot, Reisinger shows that this formulation leads to a unique equilibrium in the price game, even when the masses of small agents become infinitely small (i.e., when heterogeneity disappears). Moreover, this equilibrium has many reasonable properties; in particular, it is still the case that platforms price aggressively to the side that exerts the larger cross-group external effect; the difference under two-part tariffs is that the lower payment is only reflected in the transaction fee but not in the membership fee. ${ }^{29}$

The intuition for the unicity result is the following. The two types of agents react differently to a particular combination of membership and transaction fees. To keep constant the utility of a small agent (who trades less often), platforms have to balance an increase in the transaction fee with a smaller reduction of the membership fee than they would do for a normal seller. It follows that the effect on profit of a marginal change in platform $i$ 's transaction fee is no longer a constant multiple of the effect of a marginal change in $i$ 's membership fee. This multiple varies continuously as the fees change because the ratio of the two types that join platform $i$ also varies continuously. As a result, each platform has a unique optimal combination of the fees as a reaction to the price quadruple of its rival.

Insulating tariffs. An alternative approach to platform pricing is to consider that platforms set so-called 'insulating tariffs', i.e., tariffs such that after a deviation on one side, the pricing on the other side is adjusted in order to insulate the demand effect on one side and leave demand on the other side unchanged. This concept has been proposed and developed by Weyl (2010) in a monopoly setting, and Weyl and White (2016) in a duopoly setting.

Suppose that platforms adapt their pricing to insure agents against any utility loss from low participation on the other side of the market. Let us apply this alternative strategy space to our previous model of two-sided singlehoming. Instead of setting the membership fees $m_{s}^{i}$ and $m_{b}^{i}$, platforms now set the net surpluses $v_{s}^{i}$ and $v_{b}^{i}$. This change of strategic variables removes the feedback effect stemming from cross-group external effects. We should therefore expect a weaker impact of cross-group effects on equilibrium prices. We check now that this conjecture

\footnotetext{
${ }^{29}$ For a discussion of the link between heterogeneity and price instruments, see Rochet and Tirole (2006).
} 
is correct.

Recalling that $v_{s}^{i}=r_{s}+\pi n_{b}^{i}-m_{s}^{i}$ and $v_{b}^{i}=r_{b}+u n_{s}^{i}-m_{b}^{i}$, we can write membership fees as a function of participation on the other side and utilities $v_{s}^{i}$ and $v_{b}^{i}: m_{s}^{i}=r_{s}+\pi n_{b}^{i}-v_{s}^{i}$ and $m_{b}^{i}=r_{b}+u n_{s}^{i}-v_{b}^{i}$. If a platform sets an insulating tariff (or offers a guarantee in utils) to all agents, it fixes $v_{s}^{i}$ and $v_{b}^{i}$, which means that agents are insured against any changes in platform participation on the other side since the membership fee will be adjusted accordingly. We can then write platform $i$ 's profit as $\Pi^{i}=\left(r_{s}+\pi n_{b}^{i}-v_{s}^{i}-c_{s}\right) n_{s}^{i}+\left(r_{b}+u n_{s}^{i}-v_{b}^{i}-c_{b}\right) n_{b}^{i}$. Recalling that the participation levels $n_{s}^{i}$ and $n_{b}^{i}$ are obtained in the Hotelling fashion and can thus be expressed as a function of the guarantees, we have

$$
\begin{aligned}
\Pi^{i}= & {\left[r_{s}+\pi\left(\frac{1}{2}+\frac{v_{b}^{i}-v_{b}^{j}}{2 \tau_{b}}\right)-v_{s}^{i}-c_{s}\right]\left(\frac{1}{2}+\frac{v_{s}^{i}-v_{s}^{j}}{2 \tau_{s}}\right) } \\
& +\left[r_{b}+u\left(\frac{1}{2}+\frac{v_{s}^{i}-v_{s}^{j}}{2 \tau_{s}}\right)-v_{b}^{i}-c_{b}\right]\left(\frac{1}{2}+\frac{v_{b}^{i}-v_{b}^{j}}{2 \tau_{b}}\right) .
\end{aligned}
$$

We can now characterize the Nash equilibrium of the game in which platforms simultaneously choose guarantees. This allows us to determine the membership fees that platforms charge at equilibrium: ${ }^{30}$

$$
m_{s}^{*}=c_{s}+\tau_{s}-u / 2, \text { and } m_{b}^{*}=c_{b}+\tau_{b}-\pi / 2 .
$$

Recall that in the previous model in which platforms choose membership fees, equilibrium membership fees are equal to $c_{s}+\tau_{s}-u$ and $c_{b}+\tau_{b}-\pi$, which are lower than the ones obtained here. This confirms our initial intuition that the impact of cross-side external effects on competition is weaker when platforms offer guarantees, as there are no feedback effects on platform participation from one side to the other. The lesson to emerge from the comparison of these two models is that platforms that can compensate for utility losses due to lower than promised participation on the other side will compete less fiercely than platforms that only choose prices.

\subsubsection{Within-group external effects}

The analyses presented thus far considered exclusively cross-group external effects. Such focus seems natural as cross-group effects directly stem from the desire of the two groups of agents to interact and, thereby, give their raison d'être to two-sided platforms. However, there exist a number of situations where platforms also have to factor in the existence of within-group external effects when choosing their strategies. As explained in the introduction, these effects describe the fact that the attractiveness of a platform for the members of one group depends on the participation of the members of the very same group. Within-group effects are negative when the members of one group compete with one another to interact with the other group (e.g., Uber drivers face a given set of passengers at any location and any point in time) or because of

\footnotetext{
${ }^{30}$ See Belleflamme and Peitz (2015, pp. 671-72) for the details. Note that in contrast with the model where platforms set membership fees, an equilibrium with two active platforms exists here without having to impose that platforms be sufficiently differentiated.
} 
some form of congestion (e.g., talking about Airbnb visitors, Slee (2016) reports that "as their numbers grow, they erode the very atmosphere in which they bask and threaten the livability of the city for residents."). In contrast, there also exist sources of positive within-group effects; for instance, Belleflamme, Omrani and Peitz (2015) explain that a larger 'crowd' of funders on a crowdfunding platform increases the probability that any project will be realized, which benefits all funders. In what follows, we focus on markets with competing platforms. ${ }^{31}$ We first generalize the two-sided singlehoming model of Armstrong (2006) to allow for any type of crossand within-group external effects. We then examine the influence of within-group effects on the coexistence of platforms.

A two-sided singlehoming model encompassing within-group effects. Following Belleflamme and Toulemonde (2016b), we define the seller and buyer net surplus of visiting platform $i$ (gross of any opportunity cost) respectively as $v_{s}^{i}=r_{s}+\pi\left(n_{b}^{i}, n_{s}^{i}\right)-m_{s}^{i}$ and $v_{b}^{i}=$ $r_{b}+u\left(n_{b}^{i}, n_{s}^{i}\right)-m_{b}^{i}$. The difference with the previous model is that we use now the general functions $\pi\left(n_{b}^{i}, n_{s}^{i}\right)$ and $u\left(n_{b}^{i}, n_{s}^{i}\right)$ to represent the net gains from trade for any seller and any buyer on platform $i$. They both potentially depend on the number of buyers and on the number of sellers who are present on the platform, meaning that any form of cross-group and of withingroup external effects are permitted. Both functions are supposed to be twice continuously differentiable in their two arguments. We proceed as before by identifying the indifferent seller and buyer in the standard Hotelling fashion, which allows us to express the numbers of sellers and buyers at platform $i$ as:

$$
\left\{\begin{array}{l}
n_{b}^{i}=\frac{1}{2}+\frac{1}{2 \tau_{b}} \Delta^{u}\left(n_{b}^{i}, n_{s}^{i}\right)-\frac{1}{2 \tau_{b}}\left(m_{b}^{i}-m_{b}^{j}\right), \\
n_{s}^{i}=\frac{1}{2}+\frac{1}{2 \tau_{s}} \Delta^{\pi}\left(n_{b}^{i}, n_{s}^{i}\right)-\frac{1}{2 \tau_{s}}\left(m_{s}^{i}-m_{s}^{j}\right),
\end{array}\right.
$$

where

$$
\begin{aligned}
& \Delta^{u}\left(n_{b}^{i}, n_{s}^{i}\right) \equiv u\left(n_{b}^{i}, n_{s}^{i}\right)-u\left(1-n_{b}^{i}, 1-n_{s}^{i}\right), \\
& \Delta^{\pi}\left(n_{b}^{i}, n_{s}^{i}\right) \equiv \pi\left(n_{b}^{i}, n_{s}^{i}\right)-\pi\left(1-n_{b}^{i}, 1-n_{s}^{i}\right) .
\end{aligned}
$$

We also introduce the following notation:

$$
\begin{aligned}
& \Delta_{b}^{u} \equiv \frac{\partial \Delta^{u}\left(n_{b}^{i}, n_{s}^{i}\right)}{\partial n_{b}^{i}}, \Delta_{s}^{u} \equiv \frac{\partial \Delta^{u}\left(n_{b}^{i}, n_{s}^{i}\right)}{\partial n_{s}^{i}}, \\
& \Delta_{b}^{\pi} \equiv \frac{\partial \Delta^{\pi}\left(n_{b}^{i}, n_{s}^{i}\right)}{\partial n_{b}^{i}}, \Delta_{s}^{\pi} \equiv \frac{\partial \Delta^{\pi}\left(n_{b}^{i}, n_{s}^{i}\right)}{\partial n_{s}^{i}} .
\end{aligned}
$$

In words, the function $\Delta^{u}\left(n_{b}^{i}, n_{s}^{i}\right)$ measures the differential in buyers' net gains from trade between platforms $i$ and $j$ when there are $n_{b}^{i}$ buyers and $n_{s}^{i}$ sellers on platform $i$. The derivatives

\footnotetext{
${ }^{31}$ For an analysis with within-group external effects on monopoly platforms, see Nocke, Peitz, and Stahl (2007). They revisit the question of socially excessive or insufficient entry of monopolistically competitive sellers when the monopoly platform can charge only sellers for their listing service, and compare their findings to what happens with alternative governance structures of the platform.
} 
$\Delta_{b}^{u}$ and $\Delta_{s}^{u}$ measures the sensitivity of this differential to a change in the mass of, respectively, buyers or sellers on platform $i$; the function $\Delta^{\pi}\left(n_{b}^{i}, n_{s}^{i}\right)$ and derivatives $\Delta_{b}^{\pi}$ and $\Delta_{s}^{\pi}$ are defined accordingly for sellers.

The system of equations (3) implicitly determines the demand functions for platform $i$, $n_{b}^{i}\left(m_{b}^{i}, m_{s}^{i}, m_{b}^{j}, m_{s}^{j}\right)$ and $n_{s}^{i}\left(m_{b}^{i}, m_{s}^{i}, m_{b}^{j}, m_{s}^{j}\right)$, which depend on the combination of the four fees. ${ }^{32}$ Using implicit differentiation and taking advantage of the fact that $n_{s}^{1}=n_{s}^{2}=n_{b}^{1}=n_{b}^{2}=\frac{1}{2}$ at the symmetric equilibrium, it is then possible to show that the platforms set the following membership fees at the symmetric equilibrium of the game:

$$
\begin{aligned}
& m_{s}^{*}=c_{s}+\tau_{s}-\frac{1}{2}\left(\Delta_{s}^{u}+\Delta_{s}^{\pi}\right), \\
& m_{b}^{*}=c_{b}+\tau_{b}-\frac{1}{2}\left(\Delta_{b}^{u}+\Delta_{b}^{\pi}\right),
\end{aligned}
$$

where $\Delta_{b}^{u}, \Delta_{b}^{\pi}, \Delta_{s}^{u}$, and $\Delta_{s}^{\pi}$ are evaluated at $\left(n_{b}^{i}, n_{s}^{i}\right)=\left(\frac{1}{2}, \frac{1}{2}\right)$. We observe that the equilibrium membership fees depend on the nature of the within- and cross-group external effects. In the complete absence of external effects within and across groups, fees would be as in the Hotelling model. The presence of positive (resp. negative) external effects from, say, sellers to buyers leads platforms to lower (resp. raise) the membership fee for sellers below (resp. above) the level that would prevail absent any external effect. This is the standard result of Armstrong (2006). We add here a new result related to the presence of external effects within groups. Positive (resp. negative) external effects within groups leads platforms to lower (resp. raise) the membership fee for the group below (resp. above) the level that would prevail absent any external effect. ${ }^{33}$

Coexistence of platforms. An interesting issue is the impact that within-side external effects may have on the coexistence of competing two-sided platforms. We have seen above that positive cross-group effects generate positive feedback loops that may lead to situations where only one platform survives at equilibrium ('winner-takes-all') unless competing platforms are sufficiently differentiated. We may conjecture, however, that negative within-side effects may contribute to break the feedback loop and, thereby, facilitate the coexistence of competing platforms, even in the absence of differentiation.

Karle, Peitz and Reisinger (2015) address this issue by examining how the degree of competition among sellers affect the possibility for non-differentiated platforms offering listing services to coexist at equilibrium. ${ }^{34}$ Recall that Belleflamme and Toulemonde (2016b) defined the seller

\footnotetext{
${ }^{32}$ It is assumed that the functions $u$ and $\pi$ are such that the system (3) leads to a unique solution $\left(n_{b}^{i}, n_{b}^{i}\right) \in$ $(0,1)^{2}$, which is well-behaved in the sense that both $n_{b}^{i}$ and $n_{i}^{s}$ are decreasing functions of $\left(m_{b}^{i}-m_{b}^{j}\right)$ and $\left(m_{s}^{i}-m_{s}^{j}\right)$.

${ }^{33}$ To be sure, we recover the previous results by setting $\pi\left(n_{b}^{i}, n_{s}^{i}\right)=\pi n_{b}^{i}$ and $u\left(n_{b}^{i}, n_{s}^{i}\right)=u n_{s}^{i}$ (i.e., cross-group effects are positive and linear and within-group effects are nil). We have then $\Delta^{\pi}=\pi\left(2 n_{b}^{i}-1\right), \Delta^{u}=u\left(2 n_{s}^{i}-1\right)$, $\Delta_{b}^{\pi}=2 \pi, \Delta_{s}^{u}=2 u$, and $\Delta_{s}^{\pi}=\Delta_{b}^{u}=0$. It follows that $m_{s}^{*}=c_{s}+\tau_{s}-u$ and $m_{b}^{*}=c_{b}+\tau_{b}-\pi$.

${ }^{34}$ Ellison and Fudenberg (2003) and Ellison, Fudenberg and Möbius (2004) also show that negative within-side effects may contribute to the coexistence of two-sided platforms. Hagiu (2009) introduces competition among sellers on a two-sided platform; competition stems from consumers' variable preference for variety over sellers' products, which turns out to be a key factor determining the optimal pricing structure either of a monopoly platform or of competing platforms.
} 
and buyer net surplus of visiting platform $i$ respectively as $v_{s}^{i}=r_{s}+\pi\left(n_{b}^{i}, n_{s}^{i}\right)-m_{s}^{i}$ and $v_{b}^{i}=r_{b}+u\left(n_{b}^{i}, n_{s}^{i}\right)-m_{b}^{i}$. A special case is that the profit per buyer depends on the number competing sellers on the platform and platforms only charge sellers, $v_{s}^{i}=r_{s}+n_{b}^{i} \pi\left(n_{s}^{i}\right)-m_{s}^{i}$ and $v_{b}^{i}=r_{b}+n_{s}^{i} u$. Using these surplus functions, Karle, Peitz and Reisinger (2015) analyze the two-sided singlehoming model in which buyers observe product offering on a platform only after having visited the platform. If all sellers co-locate on the same platform then, in equilibrium, all buyers will be active on this platform. Thus there is agglomeration in equilibrium and network effects are fully exploited. In this equilibrium all profits are competed away and both platforms make zero profits.

However, imperfect competition between sellers may lead to a different equilibrium in which both platforms have a positive number of users and make positive profits in equilibrium. Suppose that there are two sellers that have to decide whether to join platform 1, join platform 2 or not to participate at all. If they both join the same platform, they obtain duopoly profit $\pi^{d}$ per buyer, which is less than monopoly profit $\pi^{m}$ per buyer they would obtain if they were the only seller on the platform. If $\pi^{m}$ is sufficiently large, there is an equilibrium in which sellers list on different platforms. Buyers are indifferent between the two platforms. Profits are not competed away; platforms can extract the full seller surplus in equilibrium.

Belleflamme and Toulemonde (2009) propose another way to address this issue. They examine the extent to which negative within-group effects among sellers may help a new platform operator lure buyers and sellers away from an existing platform. In their model, only the new platform can set membership fees; there is no price competition per se, but this is not a monopoly setting either as the existing platform provides buyers and sellers with an outside option. As in Caillaud and Jullien (2003), the new platform faces a 'chicken-and-egg' problem, which it tries to solve by using a divide-and-conquer pricing strategy; that is, the platform must subsidize the participation of one side (divide) and hope to recoup the loss through the membership fee it sets on the other side (conquer). The question is whether the platform can make any profit with such strategy. The answer is yes when the interaction among buyers and sellers only generates (positive) cross-group external effects. However, the presence of negative within-group effects among sellers (e.g., because they offer substitutable products) blurs the picture. Competition among sellers turns out to be a mixed blessing for the new platform. The upside is that the sellers' willingness to pay to join the new platform increases if only a few of them make the move; as a consequence, sellers are less sensitive to buyers' participation to the new platform, which alleviates the 'chicken-and-egg' problem. Yet, the downside is that it will be more costly for the new platform to attract buyers if only a small subset of the sellers join. The balance between the two effects depends on the relative strength of the within-group effects (with respect to the cross-group effects). There may be situations where entry is not profitable.

\subsubsection{Investment issues}

So far, the competition among platforms was studied in fixed environments. All the models we considered implicitly assumed that neither platforms nor their users are able to modify the 
conditions under which the interaction among the two groups is taking place. We now relax this assumption in two different ways: first, we let sellers make ex-ante investments that affect the gains from trade when they interact with buyers; second, we let platforms invest in reducing their costs of registering agents.

Seller investment incentives on a platform. Belleflamme and Peitz (2010) analyze how seller investment incentives are affected by the presence of competing for-profit platforms. Platform competition is modeled as in Armstrong (2006) and Armstrong and Wright (2007); that is, the final stages of the game are the ones we analyzed above with either both sides singlehoming, or one or the other side being allowed to multihome. The novelty is to add an initial stage where sellers have the possibility to make long-term investments, which may take the form of cost reduction, quality improvement or marketing measures that facilitate price discrimination or expand demand. These investments affect the surpluses, $\pi$ and $u$, that sellers and buyers obtain when they trade on the platforms. Typically, investments in cost reduction or quality improvement increase both $\pi$ and $u$, while investments in better price discrimination increase $\pi$ while decreasing $u$.

To assess the impact that for-profit platforms have on investment incentives, two trading environments are contrasted. The first is the one we are considering in this section and is called 'intermediated trade': trade takes place through for-profit intermediaries, which set membership fees on both sides of the market. The other environment is called 'non-intermediated trade', as trade is assumed to take place via open trading platforms, which can be accessed without charge.

One could think that seller investment incentives would be weaker in the intermediated trade environment, simply because the for-profit intermediaries capture part of the rents that are available in the market. However, this reasoning is short-sighted because investments also affect the membership fees that platforms set at equilibrium. Why? Because seller investments modify the intensity of the cross-group external effects and, thereby, the competition between the platforms. In particular, investments that increase buyer surplus lead platforms to lower their fee on the seller side. As a consequence, sellers internalize changes in buyer surplus if products are traded on for-profit platforms, whereas they do not in the context of open platforms. It follows that investment incentives can be stronger with competing for-profit platforms than with open platforms. The exact relationship between investment incentives and for-profit intermediation depends on which side of the market singlehomes and on the nature of the investment effort. In general, it can be said that as the intensity of competition for sellers increases, proprietary platforms are more likely to provide better seller investment incentives than open platforms. Indeed, this happens when the nature of platform competition moves from multihoming sellers and singlehoming buyers to singlehoming sellers and buyers, and then to singlehoming sellers and multihoming buyers. 
Platform investment incentives. To study the investment incentives of competing platforms, we need first to solve a game of price competition among asymmetric platforms. Belleflamme and Toulemonde (2016a) do so for the two-sided singlehoming model of Armstrong (2006). We present here a simplified version of their work by letting only marginal costs differ across platforms (all the other parameters, in particular, the cross-group external effects, remain common to the two platforms). Let $c_{s}^{i}$ and $c_{b}^{i}$ denote the marginal cost for platform $i$ of registering, respectively, an extra seller and an extra buyer; let also $\gamma_{s} \equiv c_{s}^{i}-c_{s}^{j}$ and $\gamma_{b} \equiv c_{b}^{i}-c_{b}^{j}$ $(i, j=1,2 ; i \neq j)$. Repeating all the steps described in Section 4.3.1, they find the following equilibrium membership fees for the two platforms $(i, j=1,2 ; i \neq j)$ :

$$
\begin{aligned}
& m_{s}^{i *}=c_{s}^{i}+\tau_{s}-u-\frac{1}{3} \gamma_{s}-\frac{1}{3 D}(\pi-u)\left[(2 \pi+u) \gamma_{s}+3 \tau_{s} \gamma_{b}\right], \\
& m_{b}^{i *}=c_{b}^{i}+\tau_{b}-\pi-\frac{1}{3} \gamma_{b}-\frac{1}{3 D}(u-\pi)\left[(2 u+\pi) \gamma_{b}+3 \tau_{s} \gamma_{s}\right],
\end{aligned}
$$

where $D \equiv 9 \tau_{s} \tau_{b}-(2 \pi+u)(\pi+2 u)$ is positive. ${ }^{35}$

The equilibrium membership fees can be decomposed as the sum of four components: (i) the first two terms $\left(c_{k}^{i}+\tau_{k}\right)$ are the classic Hotelling formula (marginal cost + transportation cost); (ii) the third term was identified by Armstrong (2006) as the price adjustment due to cross-group external effects (the fee is decreased by the externality exerted on the other side); (iii) the fourth term is the effect of cost differences across platforms; (iv) the last term results from the interplay between cost differences and cross-group external effects. If platforms are symmetric $\left(\gamma_{k}=0\right)$, we find the same formulas as in Section 4.3.1. In the particular case where cross-side external effects are the same on the two sides $(\pi=u$, meaning here that the gains from trade are equally split among buyer and seller), all terms but the last remain. The latter result is reminiscent of what we already observed in the setting with a monopoly platform.

The equilibrium profit of platform $i$ is computed as

$$
\begin{aligned}
\Pi^{i *}= & \frac{1}{2}\left(\tau_{s}+\tau_{b}-\pi-u\right)+\frac{1}{2 D}\left(\tau_{b} \gamma_{s}^{2}+\tau_{s} \gamma_{b}^{2}\right)+\frac{1}{2 D}(\pi+u) \gamma_{s} \gamma_{b} \\
& -\frac{\gamma_{s}}{2 D}\left(6 \tau_{s} \tau_{b}+\tau_{b}(\pi-u)-(\pi+u)(2 \pi+u)\right) \\
& -\frac{\gamma_{b}}{2 D}\left(6 \tau_{s} \tau_{b}-\tau_{s}(\pi-u)-(\pi+u)(\pi+2 u)\right),
\end{aligned}
$$

with $\Pi^{j *}$ being obtained by replacing $\gamma_{s}$ by $-\gamma_{s}$, and $\gamma_{b}$ by $-\gamma_{b}$.

Belleflamme and Toulemonde (2016a) then use this equilibrium profit function to estimate platform $i$ 's incentives to invest in cost reduction. Their main contribution is to show that cross-group external effects affect incentives to invest in cost reduction through the strategic effect of this investment. The strategic effect is the effect on one platform's profit that operates through the modification of the other platform's equilibrium fees. Absent cross-group external effects, we expect the strategic effect of a lower cost to be negative if firms compete in prices over substitutable services: a lower cost for firm $A$ leads this firm to decrease its price, which leads the rival firm to decrease its price as well (because of strategic complementarity); this, in

\footnotetext{
${ }^{35}$ This follows from the second-order condition $4 \tau_{s} \tau_{b}>(\pi+u)^{2}$.
} 
turn, reduces firm $A$ 's profit, which contributes to attenuate the direct positive impact of cost reduction on profits.

The presence of cross-group external effects challenges the previous results in two major ways. First, cross-group external effects may decrease the strategic effect and they may do so to such an extent that the strategic effect outweighs the positive direct effect; it follows that the net effect of lower costs on profit becomes negative. In that case, platforms would be better off if they could increase, rather than decrease, their costs. Second, in complete contrast with the previous case, external effects may increase the strategic effect, even up to a point where it becomes positive; in the latter case, platforms would have a twofold incentive to invest in cost reduction as it would benefit them first directly and next, indirectly, through the upward adjustment of the rival platform's equilibrium prices. It is shown that for either of these extreme cases to arise, cross-group external effects must be large relatively to the intensity of competition on the two sides.

\section{Conclusion}

In intermediate microeconomics, students learn that market power, asymmetric information, and externalities are sources of market failure. Classic oligopoly theory has focused on market power; modern industrial organization has, in addition, incorporated asymmetric information into the analysis of markets. While markets with network effects have also been investigated by industrial organization economists at least since the beginning 1980s, more recent efforts investigate decision making by intermediaries in markets characterized by imperfect competition and external effects. A particular focus lies on market environments in which a platform caters to multiple audiences, which are distinct, but connected.

A number of theoretical insights have been derived, some of which are reviewed in this chapter. This chapter has been silent regarding the empirical literature on network effects and platforms. An early guide to empirical work on two-sided platforms is Rysman (2009). Quite some work has been done in the context of media markets; we refer the reader to the overviews by Chandra and Kaiser (2015), Crawford (2015), and Sweeting (2015).

This chapter has ignored recent work on competition policy issues regarding two-sided platforms. A case in point is the analysis of price-partity clauses imposed by platforms (see, in particular, Edelman and Wright, 2015). Also, there is a well-developed literature on payment systems in which the two-sidedness of the payment system is a critical feature. Finally, the twosidedness of the business model features prominently in the economic analysis of net neutrality (see Greenstein, Peitz, and Valletti, 2016). We expect the analysis of two-sided platforms to be one of the most active areas of research in industrial organization theory in the years to come. 


\section{References}

[1] Ambrus, A., E. Calvano and M. Reisinger (2016). Either or Both Competition: A "TwoSided" Theory of Advertising with Overlapping Viewerships. American Economic Journal: Microeconomics 8, 189-222.

[2] Anderson, S. and S. Coate (2005). Market Provision of Broadcasting: A Welfare Analysis. Review of Economic Studies 72, 947-972.

[3] Anderson, S., O. Foros and H.-J. Kind (2015). Competition for advertisers and for viewers in media markets. CEPR Discussion Paper 10608.

[4] Anderson, S., O. Foros, H.-J. Kind, and M. Peitz (2012). Media Market Concentration, Advertising Levels, and Ad Prices. International Journal of Industrial Organization 30, $321-325$.

[5] Anderson, S. and M. Peitz (2015). Media See-saws: Winner and Losers on Media Platforms, University of Mannheim Working Paper 15-16.

[6] Anderson, S. and M. Peitz (2016). Advertising Congestion in Media Markets. Unpublished manuscript.

[7] Armstrong, M. (1998). Network Interconnection in Telecommunications. Economic Journal $108,545-564$.

[8] Armstrong, M. (2006). Competition in Two-sided Markets. Rand Journal of Economics 37, 668-691.

[9] Armstrong, M. and J. Wright (2007). Two-sided Markets, Competitive Bottlenecks and Exclusive Contracts. Economic Theory 32, 353-380.

[10] Belleflamme, P., N. Omrani and M. Peitz (2015). The Economics of Crowdfunding Platforms. Information Economics and Policy 33, 11-28.

[11] Belleflamme, P. and M. Peitz (2010). Platform Competition and Seller Investment Incentives. European Economic Review 54, 1059-1076.

[12] Belleflamme, P. and M. Peitz (2015). Industrial Organization: Markets and Strategies. 2nd edition. Cambridge: Cambridge University Press.

[13] Belleflamme, P. and M. Peitz (2016). Platform Competition: Who Benefits from Multihoming? Unpublished manuscript, University of Mannheim.

[14] Belleflamme, P. and E. Toulemonde (2009). Negative Intra-Group Externalities in TwoSided Markets. International Economic Review 50, 245-272. 
[15] Belleflamme, P. and E. Toulemonde (2016a). Tax Incidence on Competing Two-Sided Platforms: Lucky Break or Double Jeopardy. CORE Discussion Paper 2016/12.

[16] Belleflamme, P. and E. Toulemonde (2016b). Who Benefits from Increased Competition among Sellers on B2C Platforms? Forthcoming in Research in Economics.

[17] Cabral, L. (2011). Dynamic Price Competition with Network Effects. Review of Economic Studies 78, 83-111.

[18] Caillaud, B. and B. Jullien (2001). Competing cybermediaries. European Economic Review (Papers and Proceedings) 45, 797-808.

[19] Caillaud, B. and B. Jullien (2003). Chicken and Egg: Competition among Intermediation Service Providers. Rand Journal of Economics 34, 521-552.

[20] Chandra, A. and U. Kaiser (2015). Newspapers and Magazines, in: Anderson, S.P., Stromberg, D., Waldfogel, J. (eds.), Handbook of Media Economics, vol 1A, Amsterdam: Elsevier, pages 397-444.

[21] Choi, J.P. (1994). Network Externality, Compatibility Choice, and Planned Obsolescence. Journal of Industrial Economics 42, 167-182.

[22] Crawford, G. (2015). The Economics of Television and Online Video Markets, in: Anderson, S.P., Stromberg, D., Waldfogel, J. (eds.), Handbook of Media Economics, vol 1A, Amsterdam: Elsevier, pages 267-340.

[23] Crémer, J., P. Rey and J. Tirole (2000). Connectivity in the Commercial Internet. Journal of Industrial Economics 48, 433-472.

[24] de Bijl, P. and M. Peitz (2002). Regulation and Entry into Telecommunications Markets. Cambridge: Cambridge University Press.

[25] Doganoglu, T. and J. Wright (2015). Multihoming and Compatibility, International Journal of Industrial Organization 24, 45-67

[26] Edelman, B. and J. Wright (2015). Price Coherence and Excessive Intermediation, Quarterly Journal of Economics 130, 1283-1328.

[27] Ellison, G. and D. Fudenberg (2003). Knife-Edge or Plateau: When Do Market Models Tip? Quarterly Journal of Economics 118, 1249-1278.

[28] Ellison, G., D. Fudenberg and M. Möbius (2004). Competing Auctions. Journal of the European Economic Association 2, 30-66.

[29] European Commission (2015). Public Consultation on the Regulatory Environment for Platforms, Online Intermediaries, Data and Cloud Computing and the Collaborative Economy. Published September 2015. 
[30] Fujita, M., and J.F. Thisse (2013). Economics of Agglomeration. Cities, Industrial Location, and Globalization (2nd Edition). Cambridge: Cambridge University Press.

[31] Greenstein, S., M. Peitz and T. Valletti (2016). Net Neutrality: A Fast Lane to Understanding the Trade-offs. Journal of Economic Perspectives 30, 127-149.

[32] Grilo, I., O. Shy and J.F. Thisse (2001). Price Competition when Consumer Behavior is Characterized by Conformity or Vanity, Journal of Public Economics 80, 385-408.

[33] Hagiu, A. (2009). Two-Sided Platforms: Product Variety and Pricing Structures. Journal of Economics and Management Strategy 18,1011-1043.

[34] Hoernig, S., R. Inderst and T. Valletti (2014). Calling Circles: Network Competition with Nonuniform Calling Patterns, Rand Journal of Economics 45, 155-175.

[35] House of Lords (2016). Online Platforms and the Digital Single Market. Report published April 20, 2016.

[36] Karle, H., M. Peitz and M. Reisinger (2016). Segmentation versus Agglomeration: Competition between Platforms with Competitive Sellers. Mimeo.

[37] Katz, M. and C. Shapiro (1985). Network Externalities, Competition and Compatibility. American Economic Review 75: 424-440.

[38] Laffont, J.-J., P. Rey, and J. Tirole (1998a). Network Competition: I. Overview and Nondiscriminatory Pricing. Rand Journal of Economics 29, 1-37.

[39] Laffont, J.-J., P. Rey, and J. Tirole (1998b). Network Competition: II. Price Discrimination. Rand Journal of Economics 29, 38-56.

[40] Marshall, A. (1890). Principles of Economics, Macmillan, London (8th ed. published in 1920).

[41] Monopolkommission (2015). Competition Policy: The Challenge of Digital Markets. Special Report by the Monopolies Commission, 1 June 2015.

[42] Nocke, V., M. Peitz and K. Stahl (2007). Platform Ownership, Journal of the European Economic Association 5, 1130-1160.

[43] Peitz, M. and M. Reisinger (2015). Media Economics of the Internet, in: Anderson, S.P., Stromberg, D., Waldfogel, J. (eds.), Handbook of Media Economics, vol 1A, Amsterdam: Elsevier, pages 445-530.

[44] Reisinger, M. (2014). Two-Part Tariff Competition between Two-Sided Platforms. European Economic Review 68, 168-180.

[45] Rochet, J.-C. and J. Tirole (2003). Platform Competition in Two-sided Markets, Journal of the European Economic Association 1, 990-1024. 
[46] Rochet, J.-C. and J. Tirole (2006). Two-sided Markets: A Progress Report. Rand Journal of Economics 37, 645-667.

[47] Rysman, M. (2009). The Economics of Two-Sided Markets. Journal of Economic Perspectives 23, 125-143.

[48] Slee, T. (2016). Airbnb Is Facing an Existential Expansion Problem. Harvard Business Review. Online July 11, 2016 (https://hbr.org/2016/07/airbnb-is-facing-an-existentialexpansion-problem).

[49] Sweeting, A. (2015). Radio, in: Anderson, S.P., Stromberg, D., Waldfogel, J. (eds.), Handbook of Media Economics, vol 1A, Amsterdam: Elsevier, pages 341-396.

[50] Weyl, E. G. (2010). A Price Theory of Multi-sided Platforms. American Economic Review 100, 1642-72.

[51] Weyl, E.G. and A. White (2016). Insulated Platform Competition. Mimeo. Available at SSRN: http://ssrn.com/abstract=1694317. 